\title{
Encapsulating $N$-Heterocyclic Carbene Binuclear Transition-Metal Complexes as a New Platform for Molecular Rotation in Crystalline Solid-State
}

Mingoo Jin, ${ }^{* \dagger \$}$ Rempei Ando, ${ }^{\dagger}$ Marcus J. Jellen, "Miguel A. Garcia-Garibay,» and Hajime Ito*广\$

\footnotetext{
${ }^{\dagger}$ Division of Applied Chemistry and Frontier Chemistry Center (FCC), Faculty of Engineering, Hokkaido University, Sapporo, Hokkaido 060-8628, Japan

*Institute for Chemical Reaction Design and Discovery (WPI-ICReDD), Hokkaido University, Sapporo, Hokkaido, 060-8628, Japan

'Department of Chemistry \& Biochemistry, University of California Los Angeles, California 90095-1569, United States
}

Email:

mingoo@icredd.hokudai.ac.jp; hajito@eng.hokudai.ac.jp

\section{Contents}

SECTION

Page No.

1. General

S2

2. Synthesis

S3

3. Thermogravimetric Analysis (TGA) of Crystals 1 and 2

S5

4. Data for Single-Crystal X-Ray Structural Analyses

S6

5. Differential Scanning Calorimetry (DSC) of Crystals 1 and 2

S13

6. Solid-State NMR Studies of Crystals 1 and 2

7. DFT Calculation Study for Molecular Rotation

S16

8. Optical Properties of Solution Phase

S23

9. Photophysical Properties

S24

10. TD-DFT Calculations Studies

S26

11. Reference

S29

12. NMR Spectra

S30 


\section{General}

All commercially available reagents and solvents are reagent grade and were used without further purification unless otherwise noted. Solvents for the synthesis were purchased from commercial suppliers, degassed by three freeze-pump-thaw cycles, and further dried over molecular sieves (4 Å). NMR spectra were recorded on a JEOL JNM-ECX400P, JNM-ECS400 ( ${ }^{1} \mathrm{H}$ : 400 MHz; ${ }^{13} \mathrm{C}$ : $\left.99.5 \mathrm{MHz}\right)$ or a Bruker AVANCE III $500 \mathrm{MHz}$ spectrometer $\left({ }^{1} \mathrm{H}: 500 \mathrm{MHz} ;{ }^{13} \mathrm{C}: 125 \mathrm{MHz}\right)$ using tetramethylsilane and $\mathrm{CDCl}_{3}$ as internal standards, respectively. Solid-state NMR spectra were acquired on a Bruker AVANCE III HD $600 \mathrm{MHz}\left({ }^{2} \mathrm{H}\right.$ : $\left.92.10 \mathrm{MHz}\right)$. Emission spectra were recorded on a Hitachi F-7000 spectrometer. Absorption spectra were recorded on the basis of synchronous fluorescence spectroscopy using a Hitachi F-7000 spectrometer equipped with an integrating sphere. The emission quantum yields of the solid samples were recorded on a Hamamatsu Quantaurus-QY spectrometer with an integrating sphere. Emission lifetime measurements were recorded on a Hamamatsu Quantaurus-Tau spectrometer. Fluorescence microscopic spectra were recorded on a Photonic Hamamatsu PMA-12 Multichannel Analyzer. Elemental analyses were recorded at the Global Facility Center at Hokkaido University. Photographs were obtained using Olympus BX51 or SZX7 microscopes with Olympus DP72, Nikon D5100 digital cameras. Thermal gravimetric analysis profiles were recorded on Bruker TG-DTA2010SAT. Differential Scanning Calorimetry (DSC) profiles were measured on DSC Q2000 V24.11. The raw data files were plotted on Igor Pro Version 6.37. 


\section{Synthesis}

\subsection{Synthesis of the $\mathrm{NHC} \mathrm{Cu}(\mathrm{I})$ rotor 1}

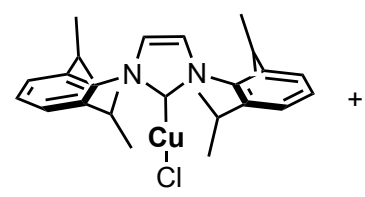

$0.2 \mathrm{mmol}$

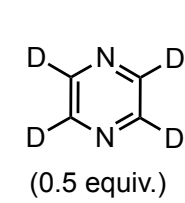

( 0.5 equiv.)
$\mathrm{Ag}\left(\mathrm{SbF}_{6}\right)$

$(0.2 \mathrm{mmol})$

THF re-crystallization

r.t., $2 \mathrm{~h} \quad$ by solvent diffusion

under $\mathrm{N}_{2}$ using DCM / Hexane

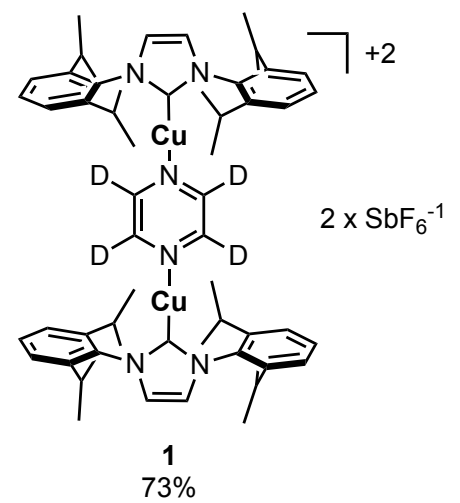

A powder of chloro[1,3-bis(2,6-diisopropylphenyl)imidazol-2-ylidene $] \mathrm{Cu}(\mathrm{I})(0.095 \mathrm{~g}, 0.20 \mathrm{mmol})$ and deuterated pyrazine $(0.009 \mathrm{~g}, 0.10 \mathrm{mmol})$ was placed in an oven-dried $19 \mathrm{ml}$ of one-neck vial. The flask was connected to a vacuum/nitrogen manifold through a rubber tube. It was evacuated and then backfilled with nitrogen. This process was repeated three times. Dry THF $(5.0 \mathrm{ml})$ was then added to the flask under nitrogen atmosphere. The reagents contained THF solution was added $\mathrm{Ag}\left(\mathrm{SbF}_{6}\right)$ and the reaction was performed under room temperature for $2 \mathrm{~h}$. The suspended THF solution was followed by separating the liquid organic layer using centrifuge. The organic layers were collected, and the solvent was removed in vacuo. Further purification by recrystallization using $\mathrm{CH}_{2} \mathrm{Cl}_{2} / \mathrm{Hexane}$ gave analytically pure light-yellowish crystals of 1 with red emission under UV light $(0.107 \mathrm{~g}, 0.07 \mathrm{mmol}$, 73 \%). ${ }^{1} \mathrm{H}$ NMR (400 MHz, $\left.\mathrm{CD}_{2} \mathrm{Cl}_{2}, \delta\right): 7.56-7.60$ (t, $\left.J=8.00,4 \mathrm{H}\right), 7.36-7.38(\mathrm{~d}, J=7.60,8 \mathrm{H}), 7.34$ (s, 4H), 2.45-2.56 (h, $J=6.93,8 \mathrm{H}), 1.23-1.25(\mathrm{~d}, J=6.80 \mathrm{~Hz}, 24 \mathrm{H}), 1.19-1.21(\mathrm{~d}, J=7.20 \mathrm{~Hz}, 24 \mathrm{H})$. ${ }^{13} \mathrm{C}$ NMR (125 MHz, $\mathrm{CD}_{2} \mathrm{Cl}_{2}$, $\delta$ ): 24.0, 25.1, 29.1, 124.8, 125.0, 131.5, 134.3, 146.1, 176.7. Anal. Calcd. for $\mathrm{C}_{58} \mathrm{H}_{72} \mathrm{D}_{4} \mathrm{Cu}_{2} \mathrm{~N}_{6} \mathrm{Sb}_{2} \mathrm{~F}_{12}$ : C, 47.65; H, 5.65; N, 5.75; Found: C, 47.90; H, 5.27; N, 5.46 . 


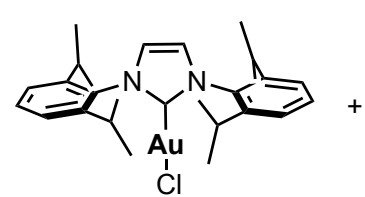

$0.2 \mathrm{mmol}$

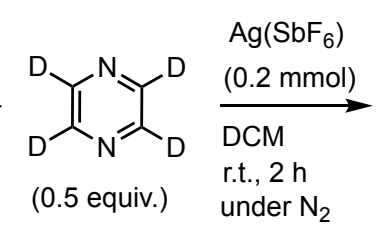

(0.5 equiv.) under $\mathrm{N}_{2}$

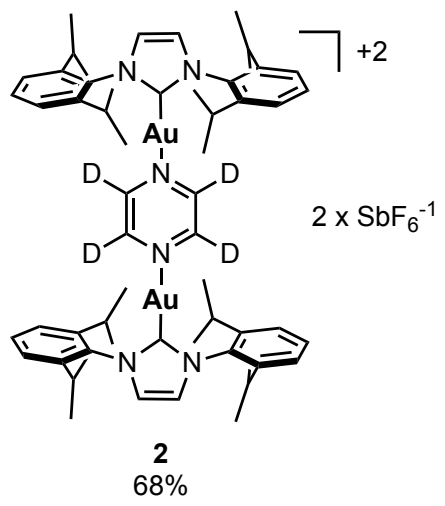

The NHC $\mathrm{Au}(\mathrm{I})$ rotor $\mathbf{2}$ was prepared from chloro[1,3-bis(2,6-diisopropylphenyl)imidazol-2ylidene] $\mathrm{Au}(\mathrm{I})$ (0.124 g, $0.20 \mathrm{mmol})$, deuterated pyrazine (0.009 g, $0.10 \mathrm{mmol})$, and $\mathrm{Ag}\left(\mathrm{SbF}_{6}\right)(0.040$ $\mathrm{g}, 0.20 \mathrm{mmol})$ according to the procedure similar to that described for the preparation of $1(0.118 \mathrm{~g}$, $0.068 \mathrm{mmol}, 68 \%$, grayish-white solid). ${ }^{1} \mathrm{H} \mathrm{NMR}\left(400 \mathrm{MHz}, \mathrm{CD}_{2} \mathrm{Cl}_{2}, \delta\right): 7.55-7.59$ (t, $\left.J=7.80,4 \mathrm{H}\right)$, $7.37-7.39(\mathrm{~d}, J=9.20,8 \mathrm{H}), 7.35(\mathrm{~s}, 4 \mathrm{H}), 2.42-2.52(\mathrm{~h}, J=6.73,8 \mathrm{H}), 1.28-1.29(\mathrm{~d}, J=7.20 \mathrm{~Hz}, 24 \mathrm{H})$, $1.23-1.25(\mathrm{~d}, J=6.80 \mathrm{~Hz}, 24 \mathrm{H}) .{ }^{13} \mathrm{C} \mathrm{NMR}\left(125 \mathrm{MHz}, \mathrm{CD}_{2} \mathrm{Cl}_{2}, \delta\right): 24.1,24.8,29.3,125.0,125.3,131.8$, 133.2, 146.0, 177.0. Calcd. for $\mathrm{C}_{58} \mathrm{H}_{72} \mathrm{D}_{4} \mathrm{Au}_{2} \mathrm{~N}_{6} \mathrm{Sb}_{2} \mathrm{~F}_{12}$ : C, 40.34; H, 4.67; N, 4.87; Found: C, 39.59; H, $4.26 ; \mathrm{N}, 4.36$. 


\section{Thermogravimetric Analysis (TGA) of Crystals 1 and 2}

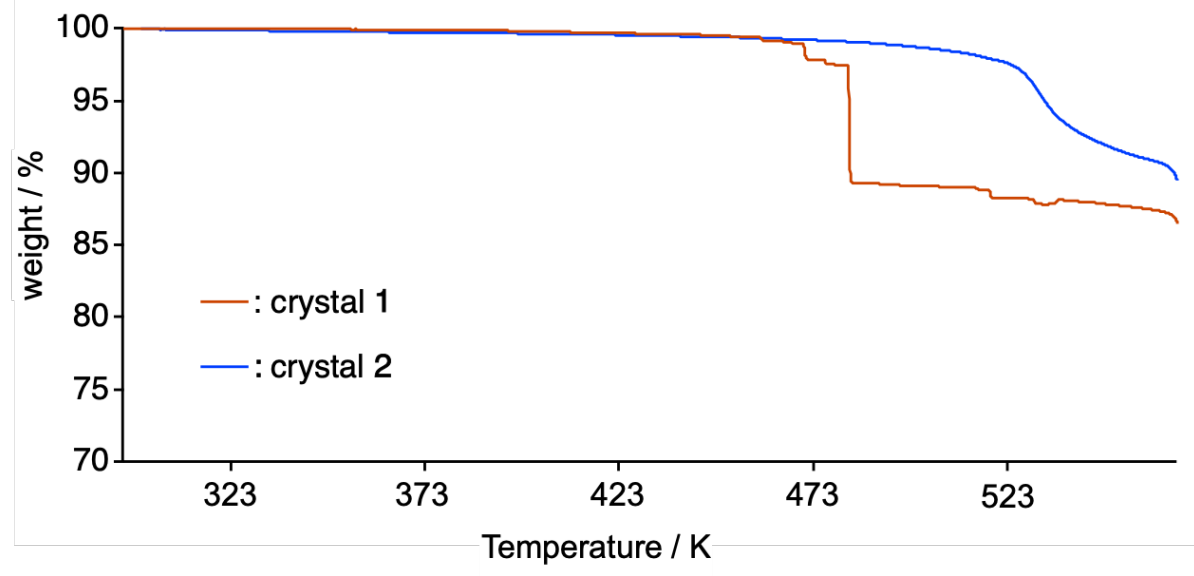

Figure S1. TGA profiles of the crystal 1 (orange line) and $\mathbf{2}$ (blue line). The heating rate is $5{ }^{\circ} \mathrm{C} / \mathrm{min}$. There was no significant decrease in weight of the samples until decomposition at approximately 470 $\mathrm{K}$. 


\section{Data for Single-Crystal X-Ray Structural Analyses}

Single-crystal X-ray structural analyses were carried out on a Rigaku XtaLAB PRO MM007 diffractometer using graphite monochromated $\mathrm{Cu}-\mathrm{K}_{\alpha}$ radiation. The structure was solved by direct methods and expanded using Fourier techniques. Non-hydrogen atoms were refined anisotropically. Hydrogen atoms were refined using the riding model. All calculations were performed using the Olex2 crystallographic software package except for refinement, which was performed using SHELXL-2013 ${ }^{1}$. 
Table S1 Summary of X-ray crystallographic data of the crystal 1 and 2.

\begin{tabular}{|c|c|c|c|}
\hline compound & 1 at $195 \mathrm{~K}$ & 1 at $250 \mathrm{~K}$ & 1 at $275 \mathrm{~K}$ \\
\hline CCDC Number & 2027530 & 2027531 & 2027532 \\
\hline Empirical Formula & $\mathrm{C}_{29} \mathrm{H}_{38} \mathrm{CuF}_{6} \mathrm{~N}_{3} \mathrm{Sb}$ & $\mathrm{C}_{29} \mathrm{H}_{38} \mathrm{CuF}_{6} \mathrm{~N}_{3} \mathrm{Sb}$ & $\mathrm{C}_{29} \mathrm{H}_{38} \mathrm{CuF}_{6} \mathrm{~N}_{3} \mathrm{Sb}$ \\
\hline Formula Weight & 727.91 & 727.91 & 727.91 \\
\hline Crystal System & monoclinic & monoclinic & monoclinic \\
\hline Crystal Size / mm & $0.35 \times 0.33 \times 0.32$ & $0.34 \times 0.33 \times 0.33$ & $0.34 \times 0.34 \times 0.33$ \\
\hline$a / \AA$ & $11.88340(10)$ & $11.94546(10)$ & $11.97178(11)$ \\
\hline$b / \AA$ & $14.12370(10)$ & $14.15596(14)$ & $14.16779(13)$ \\
\hline$c / \AA$ & $19.6903(2)$ & $19.78395(17)$ & $19.82944(17)$ \\
\hline$\alpha /^{\circ}$ & 90 & 90 & 90 \\
\hline$\beta /^{\circ}$ & $106.2540(10)$ & $106.3123(9)$ & 106.3401(9) \\
\hline$\gamma /{ }^{\circ}$ & 90 & 90 & 90 \\
\hline$V / \AA^{3}$ & $3172.68(5)$ & $3210.78(5)$ & $3227.49(5)$ \\
\hline Space Group & $P 2_{1} / \mathrm{c}$ & $P 2_{1} / \mathrm{c}$ & $P 2_{1} / \mathrm{c}$ \\
\hline$Z$ value & 4 & 4 & 4 \\
\hline$D_{\text {calc }} / \mathrm{g} \mathrm{cm}^{-3}$ & 1.524 & 1.506 & 1.498 \\
\hline Temperature / K & 195 & 250 & 275 \\
\hline $2 \theta_{\max } /^{\circ}$ & 152.836 & 152.808 & 152.874 \\
\hline$\mu\left(\mathrm{Mo} \mathrm{K}_{\alpha}\right) / \mathrm{cm}^{-1}$ & 80.83 & 79.87 & 79.45 \\
\hline No. of Reflections & $\begin{array}{l}\text { Total: } 22528 \\
\text { Unique: } 6432 \\
R_{\text {int }}=0.0309\end{array}$ & $\begin{array}{l}\text { Total: } 23240 \\
\text { Unique: } 6454 \\
R_{\text {int }}=0.0308\end{array}$ & $\begin{array}{l}\text { Total: } 24498 \\
\text { Unique: } 6504 \\
R_{\text {int }}=0.0333\end{array}$ \\
\hline$R_{1}{ }^{\mathrm{a}}$ & 0.0347 & 0.0326 & 0.0403 \\
\hline$w R_{2}{ }^{\mathrm{b}}$ & 0.1142 & 0.0909 & 0.1150 \\
\hline $\begin{array}{l}\mathrm{GOF}^{c} \\
\text { Max./Mini. peak } I^{\mathrm{d}} / \AA^{3}\end{array}$ & $\begin{array}{l}0.949 \\
0.45 \mathrm{e}^{-} /-1.33 \mathrm{e}^{-} \\
\end{array}$ & $\begin{array}{l}1.055 \\
0.46 \mathrm{e}^{-} /-0.91 \mathrm{e}^{-}\end{array}$ & $\begin{array}{l}1.082 \\
0.79 \mathrm{e}^{-} /-0.76 \mathrm{e}^{-}\end{array}$ \\
\hline compound & 1 at $300 \mathrm{~K}$ & 1 at $325 \mathrm{~K}$ & 1 at $350 \mathrm{~K}$ \\
\hline CCDC Number & 2027533 & 2027534 & 2027535 \\
\hline Empirical Formula & $\mathrm{C}_{29} \mathrm{H}_{38} \mathrm{CuF}_{6} \mathrm{~N}_{3} \mathrm{Sb}$ & $\mathrm{C}_{29} \mathrm{H}_{38} \mathrm{CuF}_{6} \mathrm{~N}_{3} \mathrm{Sb}$ & $\mathrm{C}_{29} \mathrm{H}_{38} \mathrm{CuF}_{6} \mathrm{~N}_{3} \mathrm{Sb}$ \\
\hline Formula Weight & 727.91 & 727.91 & 727.91 \\
\hline Crystal System & monoclinic & monoclinic & monoclinic \\
\hline Crystal Size / mm & $0.36 \times 0.35 \times 0.35$ & $0.38 \times 0.37 \times 0.37$ & $0.38 \times 0.38 \times 0.36$ \\
\hline$a / \AA$ & $12.00159(11)$ & $12.03480(10)$ & $12.06050(10)$ \\
\hline$b / \AA$ & $14.18178(15)$ & $14.20220(10)$ & $14.2164(2)$ \\
\hline$c / \AA$ & $19.87407(19)$ & $19.9261(2)$ & $19.9658(2)$ \\
\hline$\alpha /^{\circ}$ & 90 & 90 & 90 \\
\hline$\beta /^{\circ}$ & $106.3277(10)$ & $106.3150(10)$ & $106.3220(10)$ \\
\hline$\gamma /^{\circ}$ & 90 & 90 & 90 \\
\hline$V / \AA^{3}$ & $3246.22(6)$ & $3268.64(5)$ & $3285.31(6)$ \\
\hline Space Group & $P 2_{1} / \mathrm{c}$ & $P 2_{1} / \mathrm{c}$ & $P 2_{1} / \mathrm{c}$ \\
\hline$Z$ value & 4 & 4 & 4 \\
\hline$D_{\text {calc }} / \mathrm{g} \mathrm{cm}^{-3}$ & 1.489 & 1.479 & 1.472 \\
\hline Temperature / K & 300 & 325 & 350 \\
\hline $2 \theta_{\max } /^{\circ}$ & 152.836 & 152.418 & 145.48 \\
\hline$\mu\left(\mathrm{Mo} \mathrm{K}_{\alpha}\right) / \mathrm{cm}^{-1}$ & 79.00 & 78.45 & 78.06 \\
\hline No. of Reflections & $\begin{array}{l}\text { Total: } 22875 \\
\text { Unique: } 6489 \\
R_{\text {int }}=0.0343\end{array}$ & $\begin{array}{l}\text { Total: } 25148 \\
\text { Unique: } 6572 \\
R_{\text {int }}=0.0301\end{array}$ & $\begin{array}{l}\text { Total: } 20046 \\
\text { Unique: } 6238 \\
R_{\text {int }}=0.0273\end{array}$ \\
\hline$R_{1}{ }^{\mathrm{a}}$ & 0.0416 & 0.0370 & 0.0381 \\
\hline$w R_{2}{ }^{\mathrm{b}}$ & 0.1221 & 0.1125 & 0.1371 \\
\hline $\mathrm{GOF}^{c}$ & 1.085 & 0.969 & 1.089 \\
\hline Max./Mini. peak $I^{\mathrm{d}} / \AA^{3}$ & $0.79 \mathrm{e}^{-/-0.81 \mathrm{e}^{-}}$ & $0.32 \mathrm{e}^{-/-0.98 \mathrm{e}^{-}}$ & $0.30 \mathrm{e}^{-/-1.09 \mathrm{e}^{-}}$ \\
\hline
\end{tabular}

${ }^{\mathrm{a}}: I>2.00 \sigma(I) .{ }^{\mathrm{b}}$ :All reflections. ${ }^{\mathrm{c}}$ :Goodness of Fit Indicator. ${ }^{\mathrm{d}}$ : in Final Diff. Map. 


\begin{tabular}{|c|c|c|c|}
\hline compound & 2 at $195 \mathrm{~K}$ & 2 at $250 \mathrm{~K}$ & 2 at $275 \mathrm{~K}$ \\
\hline CCDC Number & 2027536 & 2027537 & 2027538 \\
\hline Empirical Formula & $\mathrm{C}_{29} \mathrm{H}_{38} \mathrm{AuF}_{6} \mathrm{~N}_{3} \mathrm{Sb}$ & $\mathrm{C}_{29} \mathrm{H}_{38} \mathrm{AuF}_{6} \mathrm{~N}_{3} \mathrm{Sb}$ & $\mathrm{C}_{29} \mathrm{H}_{38} \mathrm{AuF}_{6} \mathrm{~N}_{3} \mathrm{Sb}$ \\
\hline Formula Weight & 861.34 & 861.34 & 861.34 \\
\hline Crystal System & monoclinic & monoclinic & monoclinic \\
\hline Crystal Size / mm & $0.61 \times 0.55 \times 0.45$ & $0.71 \times 0.6 \times 0.5$ & $0.71 \times 0.61 \times 0.52$ \\
\hline$a / \AA$ & $11.9022(11)$ & $11.9762(8)$ & $12.0155(7)$ \\
\hline$b / \AA$ & $14.2196(13)$ & $14.2322(10)$ & $14.2691(8)$ \\
\hline$c / \AA$ & $19.937(2)$ & $20.0321(11)$ & $20.0602(9)$ \\
\hline$\alpha /^{\circ}$ & 90 & 90 & 90 \\
\hline$\beta /^{\circ}$ & $105.281(10)$ & $105.388(6)$ & $105.462(5)$ \\
\hline$\gamma /{ }^{\circ}$ & 90 & 90 & 90 \\
\hline$V / \AA^{3}$ & $3254.9(6)$ & $3292.0(4)$ & $3314.9(3)$ \\
\hline Space Group & $P 2_{1} / \mathrm{c}$ & $P 2_{1} / \mathrm{c}$ & $P 2_{1} / \mathrm{c}$ \\
\hline$Z$ value & 4 & 4 & 4 \\
\hline$D_{\text {calc }} / \mathrm{g} \mathrm{cm}^{-3}$ & 1.758 & 1.738 & 1.726 \\
\hline Temperature / K & 195 & 250 & 275 \\
\hline $2 \theta_{\max } 1^{\circ}$ & 173.602 & 153.254 & 151.772 \\
\hline$\mu\left(\mathrm{Mo} \mathrm{K}_{\alpha}\right) / \mathrm{cm}^{-1}$ & 154.28 & 152.54 & 151.49 \\
\hline \multirow[t]{3}{*}{ No. of Reflections } & Total: 16273 & Total: 16505 & Total: 16771 \\
\hline & Unique: 5973 & Unique: 6086 & Unique: 6082 \\
\hline & $R_{\mathrm{int}}=0.0564$ & $R_{\mathrm{int}}=0.0557$ & $R_{\mathrm{int}}=0.0567$ \\
\hline$R_{1}{ }^{\mathrm{a}}$ & 0.1188 & 0.1088 & 0.1120 \\
\hline$w R_{2}{ }^{\mathrm{b}}$ & 0.3549 & 0.3052 & 0.3406 \\
\hline $\mathrm{GOF}^{c}$ & 1.089 & 1.132 & 1.094 \\
\hline Max./Mini. peak $I^{\mathrm{d}} / \AA^{3}$ & $3.39 \mathrm{e}^{-} /-2.27 \mathrm{e}^{-}$ & $2.36 \mathrm{e}^{-} /-2.02 \mathrm{e}^{-}$ & $2.25 \mathrm{e}^{-} /-2.02 \mathrm{e}^{-}$ \\
\hline compound & 2 at $295 \mathrm{~K}$ & 2 at $325 \mathrm{~K}$ & 2 at $350 \mathrm{~K}$ \\
\hline CCDC Number & 2027540 & 2027541 & 2027539 \\
\hline Empirical Formula & $\mathrm{C}_{29} \mathrm{H}_{38} \mathrm{AuF}_{6} \mathrm{~N}_{3} \mathrm{Sb}$ & $\mathrm{C}_{29} \mathrm{H}_{38} \mathrm{AuF}_{6} \mathrm{~N}_{3} \mathrm{Sb}$ & $\mathrm{C}_{29} \mathrm{H}_{38} \mathrm{AuF}_{6} \mathrm{~N}_{3} \mathrm{Sb}$ \\
\hline Formula Weight & 861.34 & 861.34 & 861.34 \\
\hline Crystal System & monoclinic & monoclinic & monoclinic \\
\hline Crystal Size / mm & $0.75 \times 0.65 \times 0.55$ & $0.78 \times 0.67 \times 0.55$ & $0.79 \times 0.69 \times 0.59$ \\
\hline$a / \AA$ & $12.0137(10)$ & $12.0977(14)$ & $12.1313(15)$ \\
\hline$b / \AA$ & $14.2628(11)$ & $14.3105(14)$ & $14.3728(18)$ \\
\hline$c / \AA$ & $20.0865(12)$ & $20.1580(17)$ & $20.2040(17)$ \\
\hline$\alpha /^{\circ}$ & 90 & 90 & 90 \\
\hline$\beta /^{\circ}$ & 105.393(8) & $105.261(10)$ & $105.513(11)$ \\
\hline$\gamma /{ }^{\circ}$ & 90 & 90 & 90 \\
\hline$V / \AA^{3}$ & $3318.3(4)$ & $3366.8(6)$ & $3394.4(7)$ \\
\hline Space Group & $P 2_{1} / \mathrm{c}$ & $P 2_{1} / \mathrm{c}$ & $P 2_{1} / \mathrm{c}$ \\
\hline$Z$ value & 4 & 4 & 4 \\
\hline$D_{\text {calc }} / \mathrm{g} \mathrm{cm}^{-3}$ & 1.724 & 1.699 & 1.685 \\
\hline Temperature / K & 295 & 325 & 350 \\
\hline $2 \theta_{\max } /^{\circ}$ & 173.992 & 145.872 & 146.354 \\
\hline$\mu\left(\mathrm{Mo} \mathrm{K}_{\alpha}\right) / \mathrm{cm}^{-1}$ & 151.33 & 149.15 & 147.93 \\
\hline \multirow[t]{3}{*}{ No. of Reflections } & Total: 16313 & Total: 14563 & Total: 18214 \\
\hline & Unique: 6156 & Unique: 6099 & Unique: 6311 \\
\hline & $R_{\text {int }}=0.0583$ & $R_{\mathrm{int}}=0.0650$ & $R_{\text {int }}=0.0566$ \\
\hline$R_{1}{ }^{\mathrm{a}}$ & 0.1154 & 0.1494 & 0.1290 \\
\hline$w R_{2}^{\mathrm{b}}$ & 0.3475 & 0.4533 & 0.4130 \\
\hline $\mathrm{GOF}^{c}$ & 1.064 & 1.761 & 1.520 \\
\hline Max./Mini. peak $I^{\mathrm{d}} / \AA^{3}$ & $2.27 \mathrm{e}^{-/-1.91 \mathrm{e}^{-}}$ & $6.56 \mathrm{e}^{-/-2.18 \mathrm{e}^{-}}$ & $5.15 \mathrm{e}^{-/-1.89 \mathrm{e}^{-}}$ \\
\hline
\end{tabular}


a)

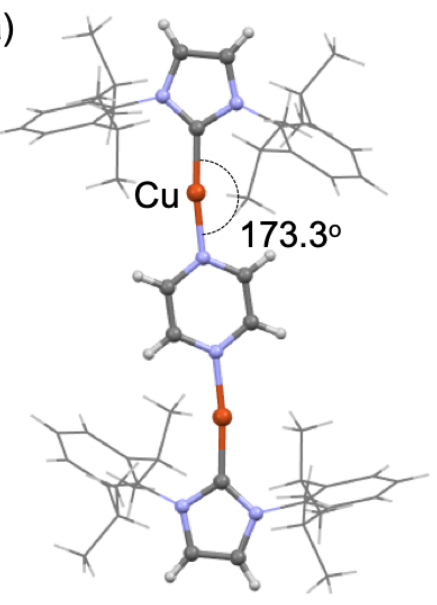

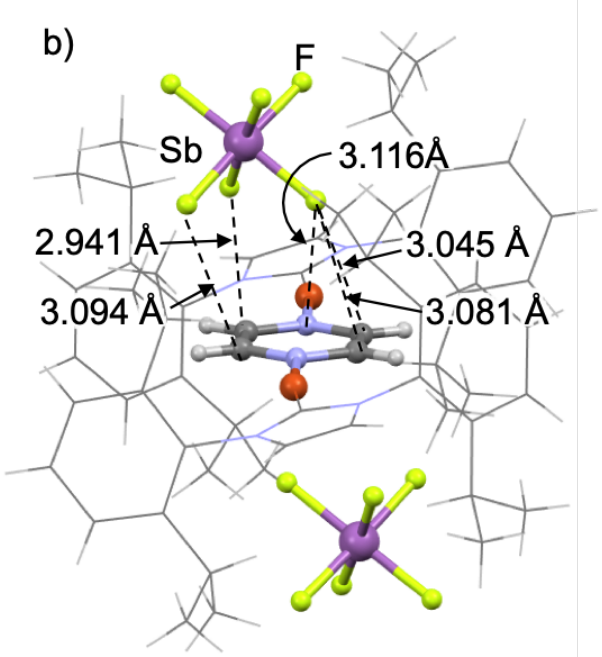

c)

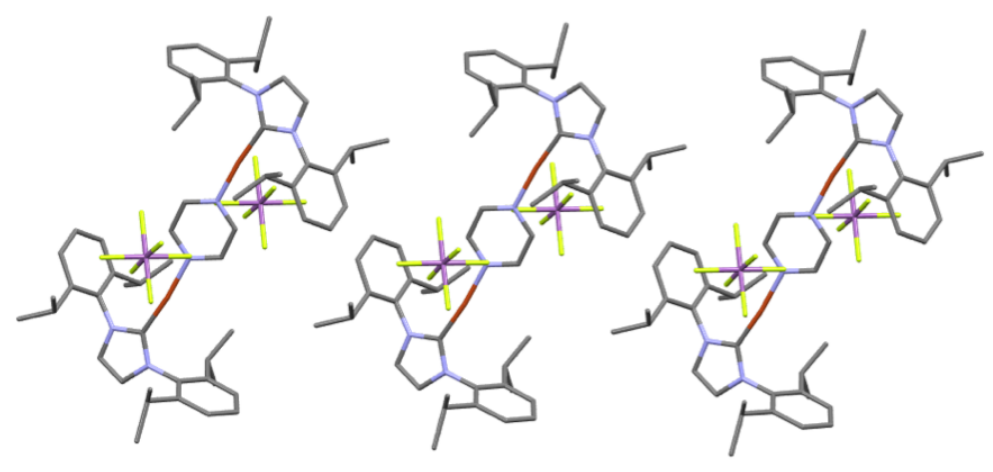

d)

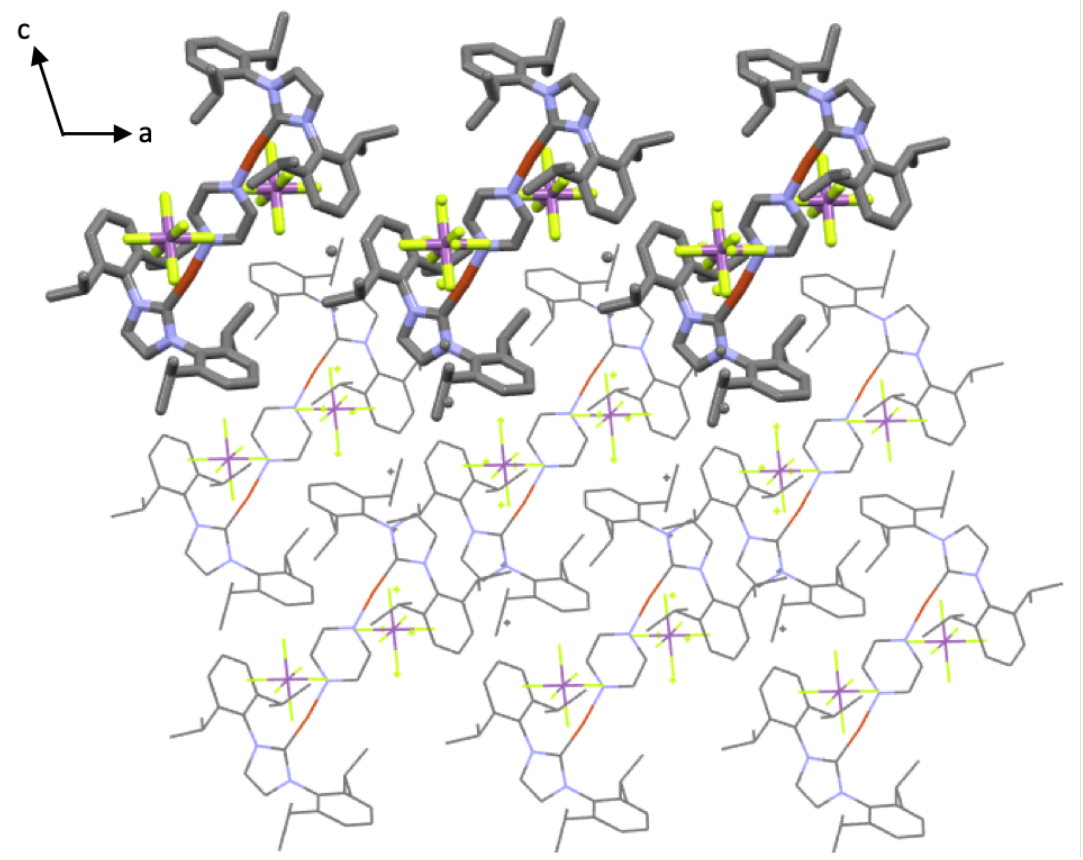

Figure S2. Crystal structure of crystal 1 at $195 \mathrm{~K}$. H atoms are omitted for clarity in c) and d). 
a)

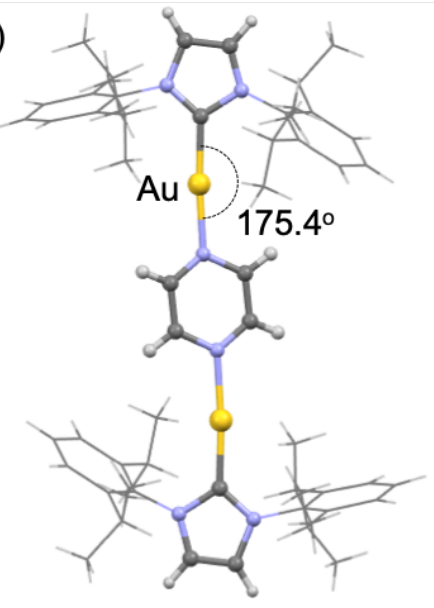

b)

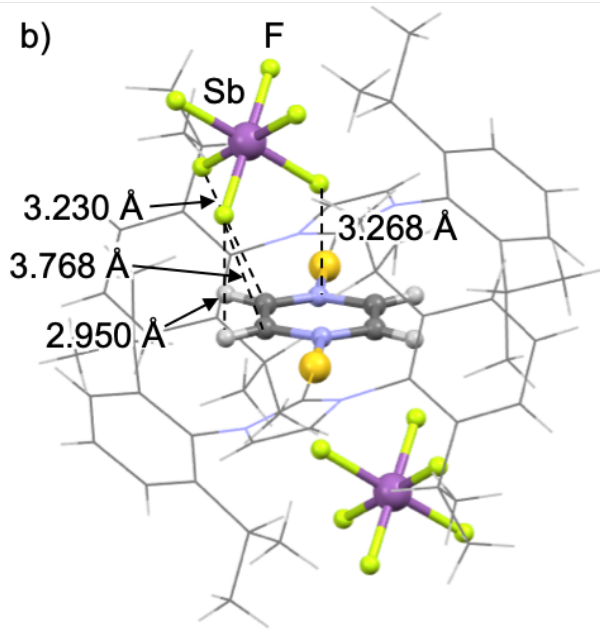

c)

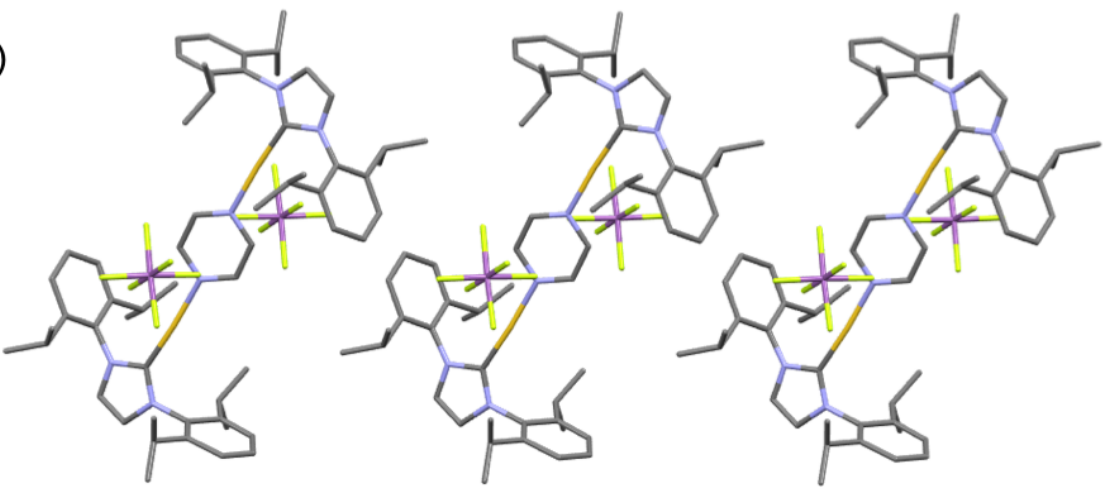

d)

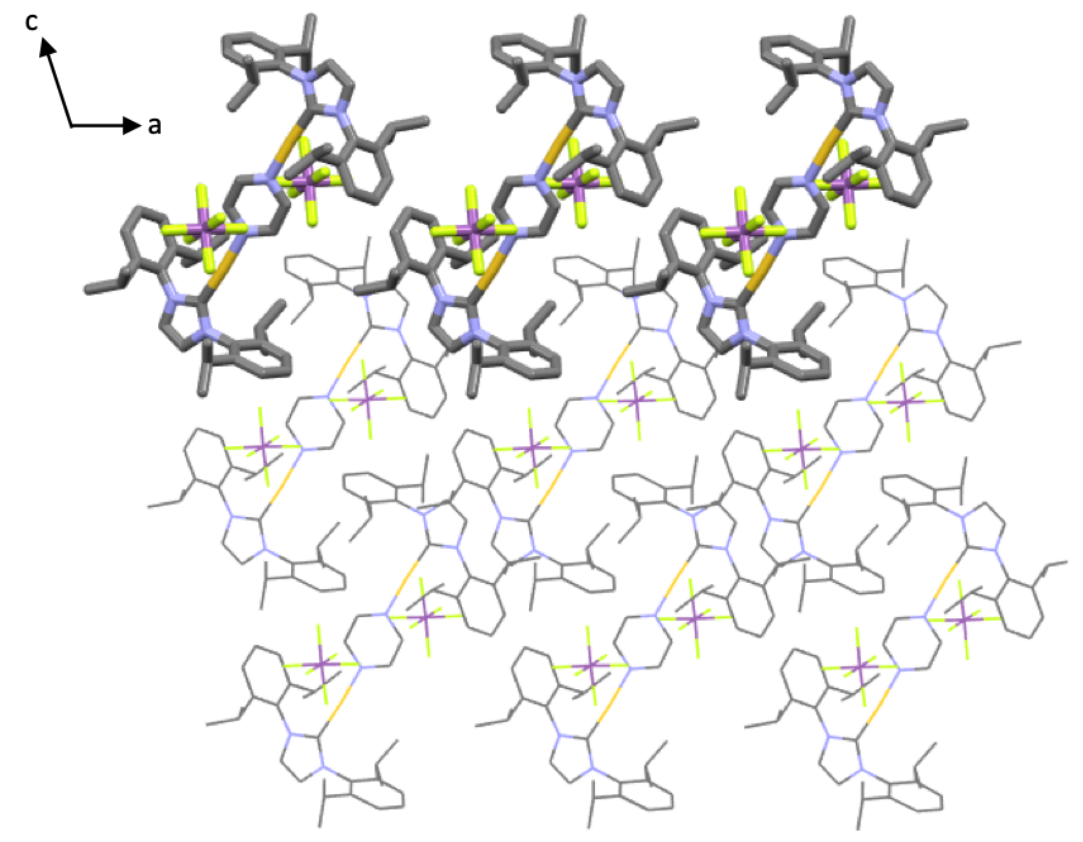

Figure S3. Crystal structure of crystal 2 at 195 K. H atoms are omitted for clarity in c) and d). 


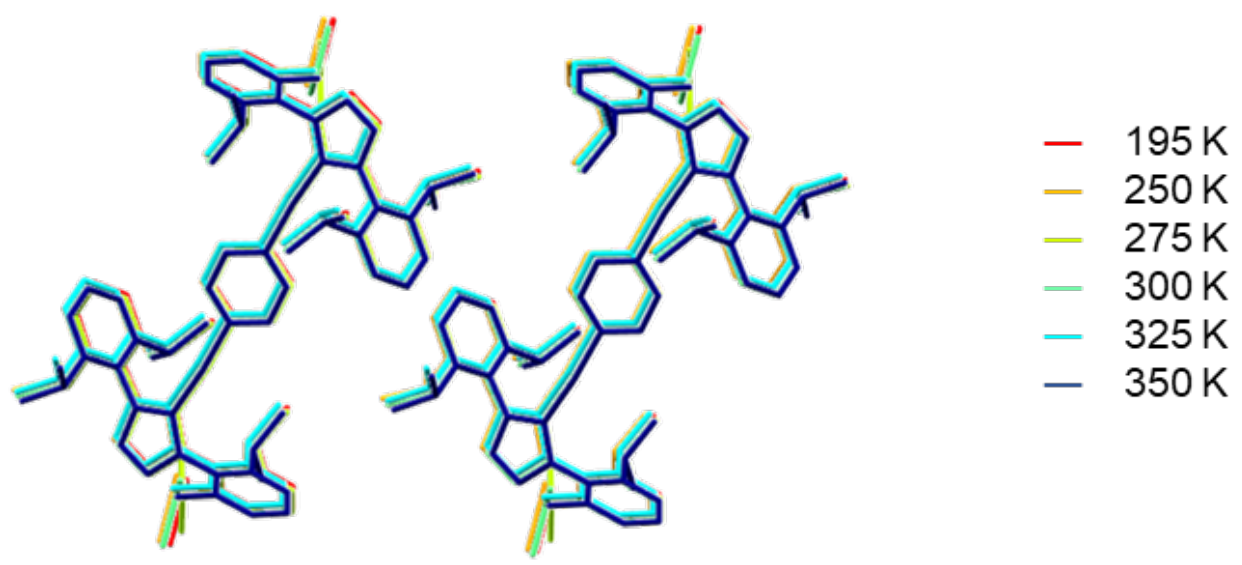

Figure S4. Superimposition of the crystal 1 obtained at $195 \mathrm{~K}$ to $350 \mathrm{~K}$.

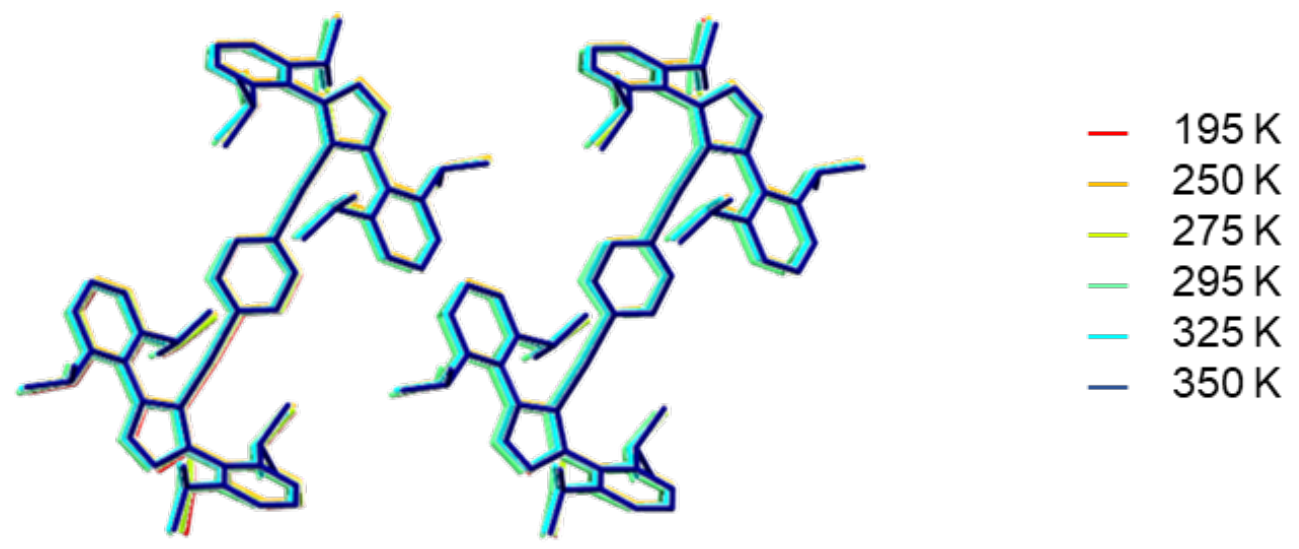

Figure S5. Superimposition of the crystal 2 obtained at $195 \mathrm{~K}$ to $350 \mathrm{~K}$. 

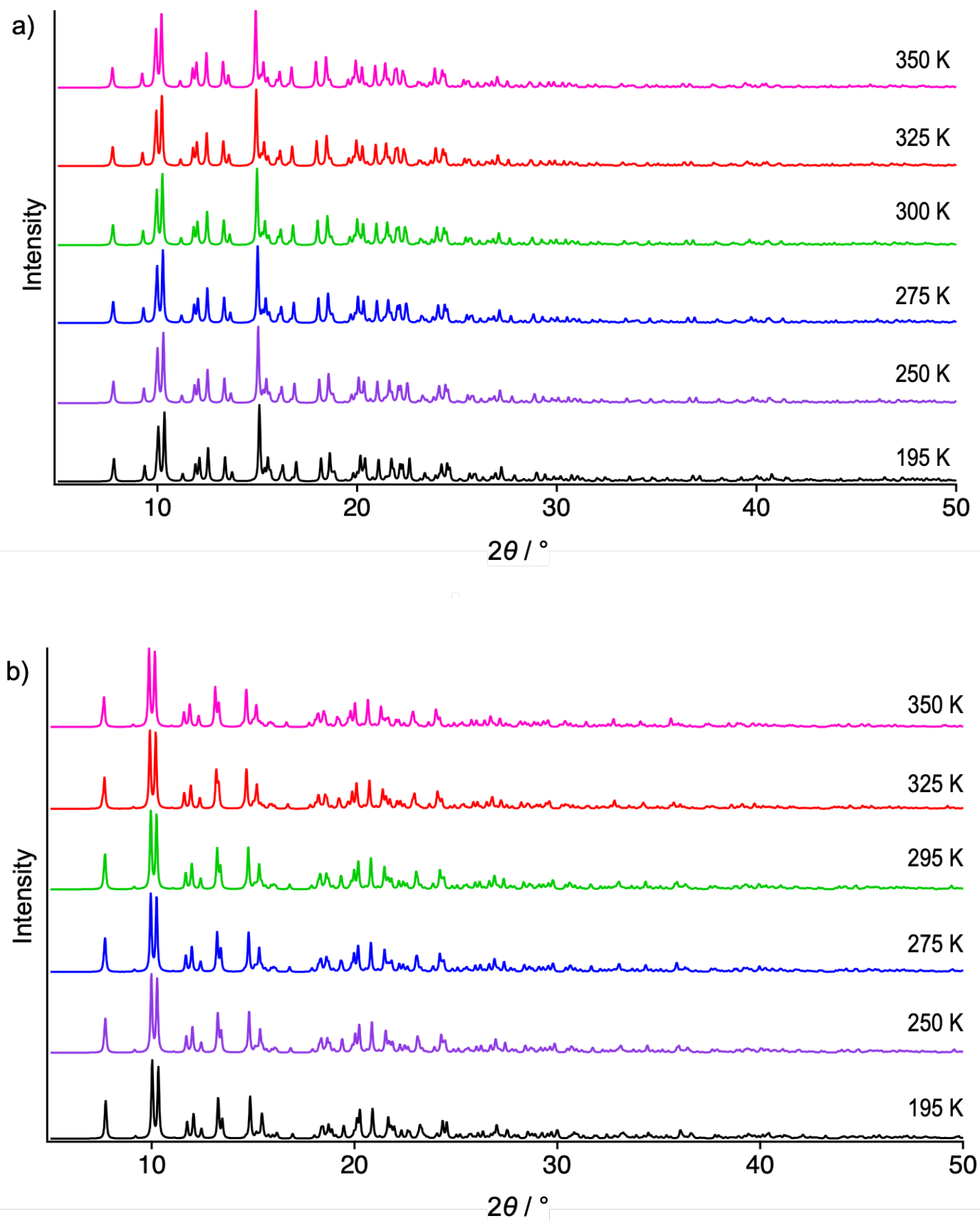

Figure S6. Simulated PXRD patterns derived from the VT-single crystal structures of a) 1 and b) 2 taken between $195 \mathrm{~K}$ and $350 \mathrm{~K}$. 


\section{Differential Scanning Calorimetry (DSC) of Crystals 1 and 2}
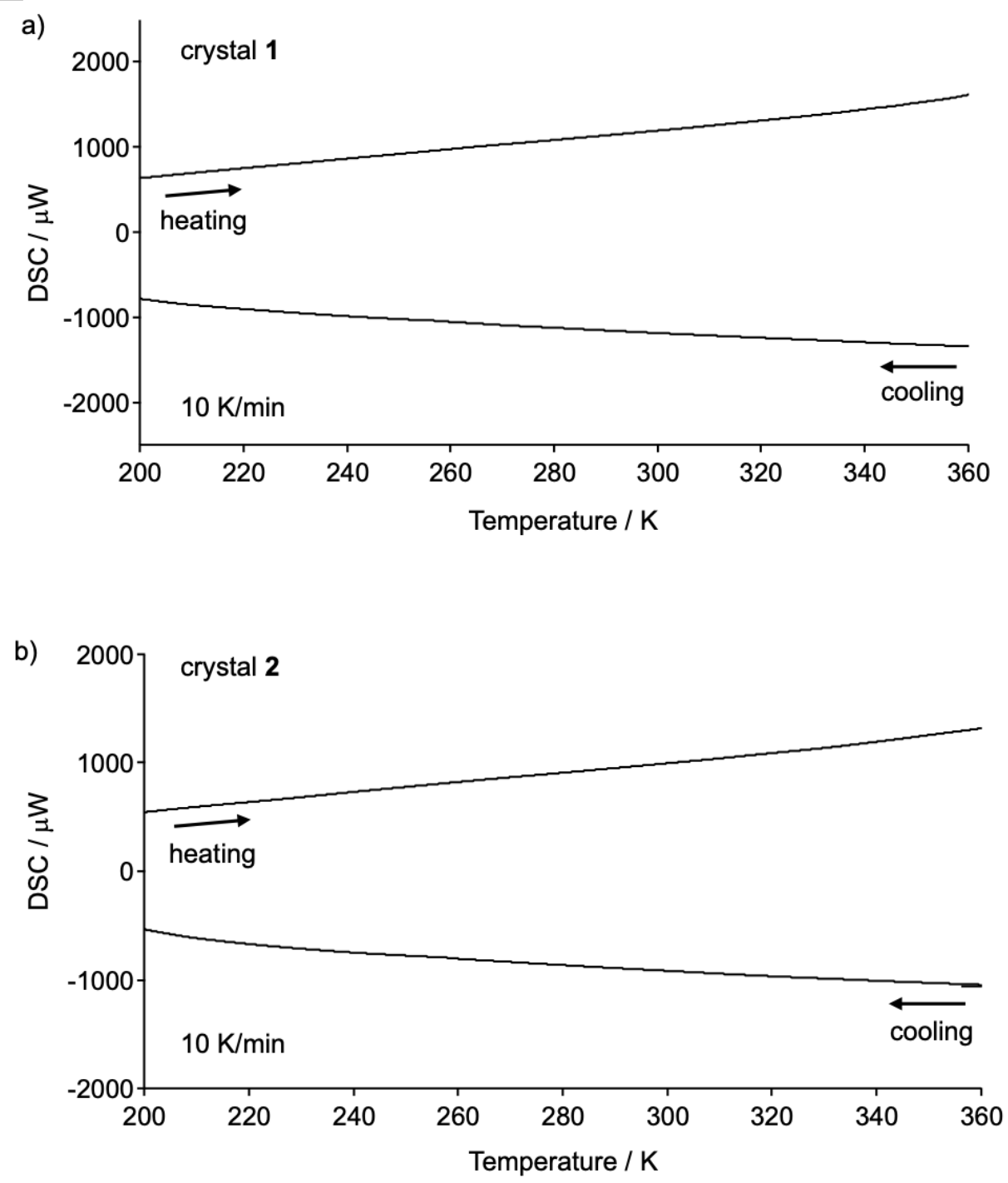

Figure S7. DSC profiles of a) the crystal 1 and b) 2 . Heating and cooling rates were $10 \mathrm{~K} / \mathrm{min}$. (Temperature range: $200 \mathrm{~K}-360 \mathrm{~K}$ ) 


\section{Solid-State NMR Studies of Crystals 1 and 2}

\subsection{Solid-state ${ }^{2}$ H NMR Spin-echo Experiments}

The solid-state ${ }^{2} \mathrm{H}$ NMR (SS ${ }^{2} \mathrm{H}$ NMR) spin-echo experiments in this work were performed on a Bruker AV600 instrument at $92.1 \mathrm{MHz}$ (deuterium resonance frequency) with a $5 \mathrm{~mm}$ wide line probe and 90-degree pulse of $2.9 \mu \mathrm{s}$. For suppression of the undesired artifacts, a quadrupolar-echo sequence with phase recycling was used. An echo delay of $50 \mu$ s was used after the refocusing delay of $46 \mu \mathrm{s}$, and the recycle delay between pulses was 30s. About $250 \mathrm{mg}$ of sample was placed in a short borosilicate glass NMR tube for each experiment. 512 scans or more were used to acquire each spectrum. All spectra in this work were obtained using a line broadening of $5.0 \mathrm{kHz}$ in the data processing.

\subsection{Simulation of the Experimental Spectra}

All simulation was performed utilizing the online program offered by professor $\mathrm{H}$. W. Spiess. ${ }^{2}$ The spectra obtained for crystals 1 and $\mathbf{2}$ were identified to be the result of 2-fold rotational model (Figure S8). Basically, a quadrupolar coupling constant (QCC) of $110 \mathrm{kHz}$, a cone angle of $60^{\circ}$ formed between the rotational 1,4-axis and C-D bond vector, and Brownian jumps of $180^{\circ}$ were used. Additionally, the case of crystal 1 were required to apply $15 \%$ of static contributions with a $\log$ Gaussian distribution of the rotational jumping rates having a width $\mathrm{s}=0.5$. In the case of crystal 2, the spectra at $275 \mathrm{~K}$ applied $10 \%$ of static contribution with the log-Gaussian function used in crystal 1. 

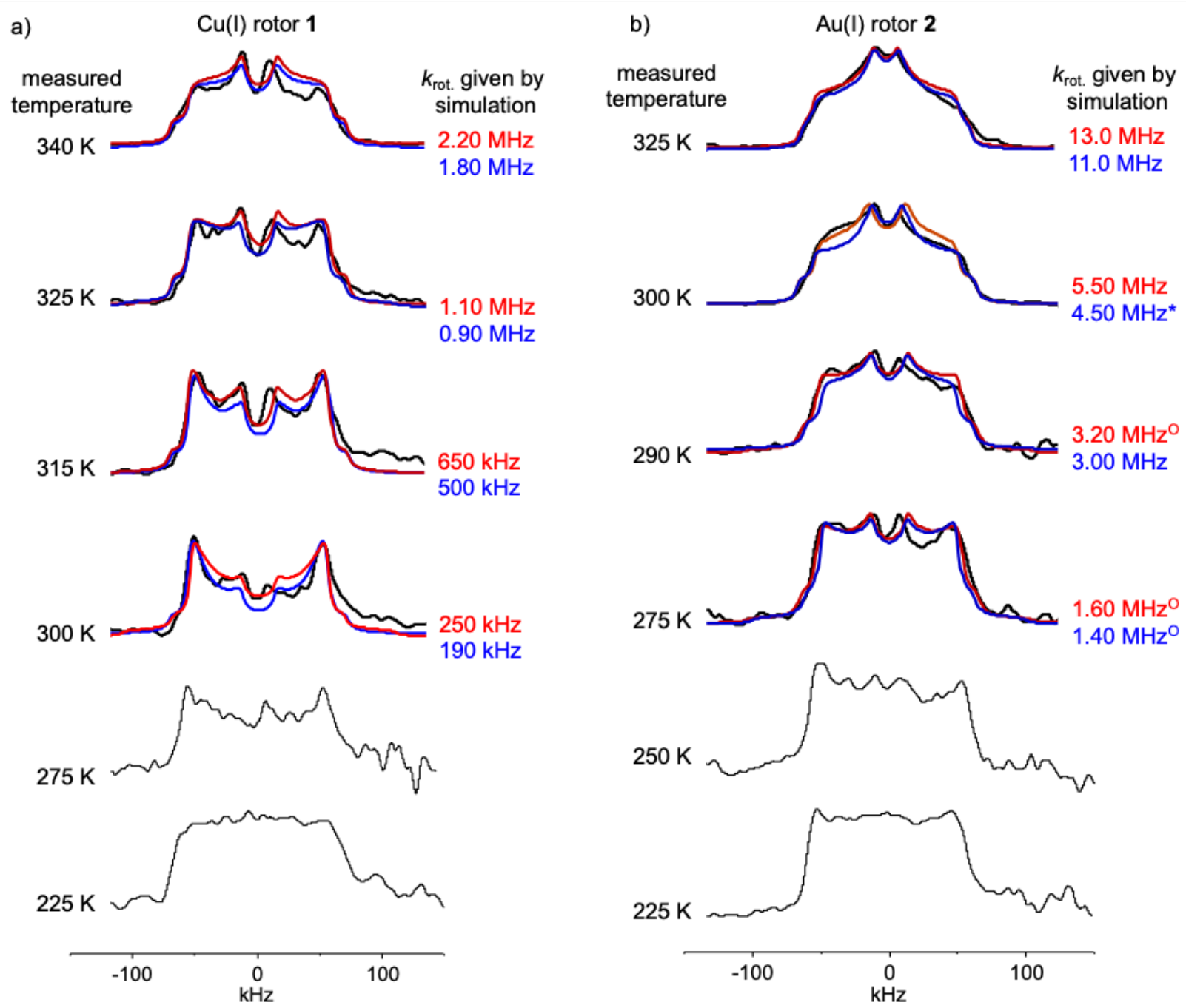

Figure S8. Variable temperature (VT) solid-state ${ }^{2} \mathrm{H}$ NMR spectra of the crystal a) $\mathbf{1}$ and b) $\mathbf{2}$ obtained from the experiment (solid black line) and the simulation with rotation frequency $k_{\text {rot. }}$ (solid red and blue line). ${ }^{\mathrm{O}}$ : applying $10 \%$ of static contribution via logGauss function. *: using 0.8 of asymmetry factor. 


\section{DFT Calculation Study for Molecular Rotation}

\subsection{Details of DFT calculations for the ground state and TS with NBO analysis}

All geometry optimizations and thermal energy correction calculations (frequency analyses) using density functional theory (DFT) were performed with Gaussian 16 programs ${ }^{3}$. The initial geometries of both NHC cationic metal complexes were taken from the crystal structures, followed by optimizing the positions of $\mathrm{H}$ atoms with fixing the geometries of heavy atoms using DFT calculation with B3LYP/6-31G level. The ground states were obtained by geometry optimization using $\omega B 97 X D / 6-31 G(d)$ for organic atoms and LanL2DZ for metals with fixing whole atoms without pyrazine rotator to represent the origins of crystal packing environment. Under the fixation of whole atoms without pyrazine rotator, the geometries of transition states (TS) for the 2-fold rotation of rotor 1 and 2 were obtained by the Locally Updated Planes (LUP) method, which is one of conventional path optimization calculations using the GRRM17 program $^{4-6}$. Natural bond orbital (NBO) analysis of the obtained TS structures of 1 and $\mathbf{2}$ have been performed by using $\omega \mathrm{B} 97 \mathrm{XD} / 6-31 \mathrm{G}(\mathrm{d})$ for organic atoms and LanL2DZ for metals on NBO 7.0 programs ${ }^{7,8}$.

a)

ground state structure of $\mathrm{Cu}(\mathrm{I})$ rotor 1
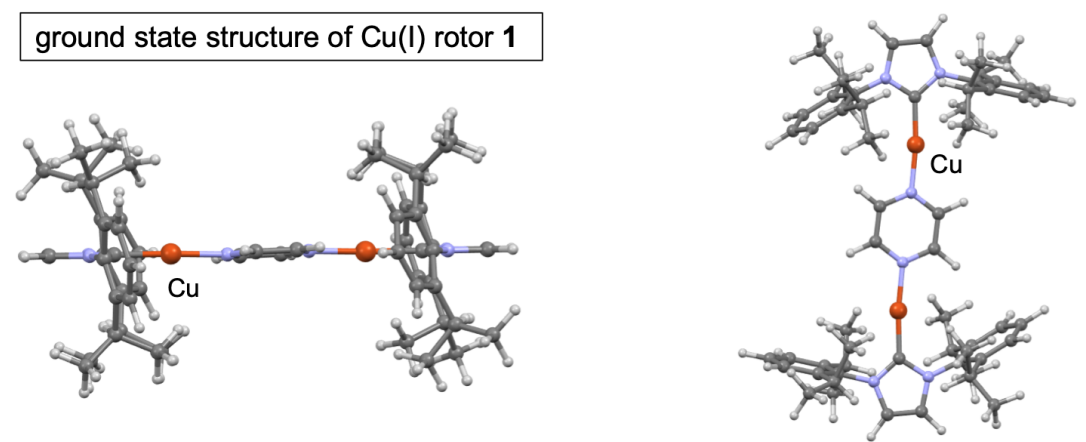

b)
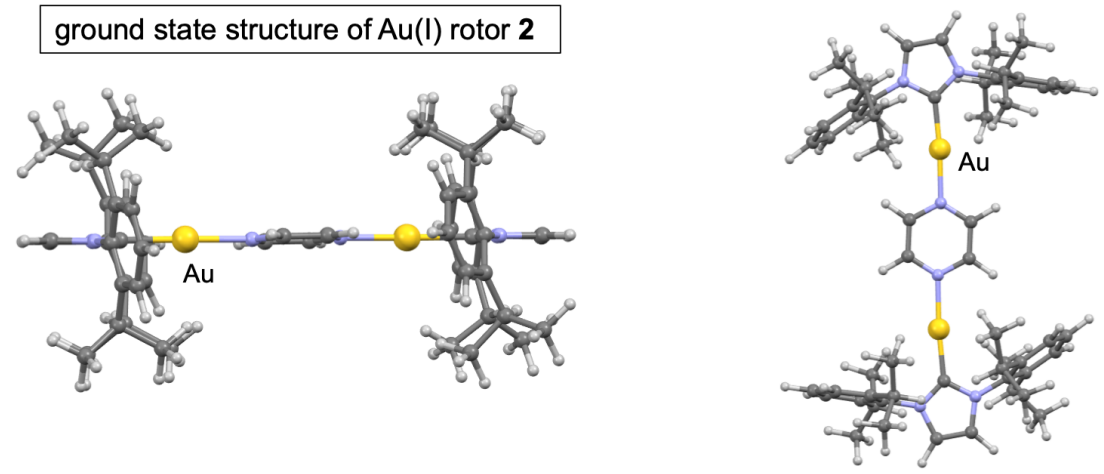

Figure S9. Geometries of the ground state of a) 1 and b) 2 obtained from the calculations. 
a)
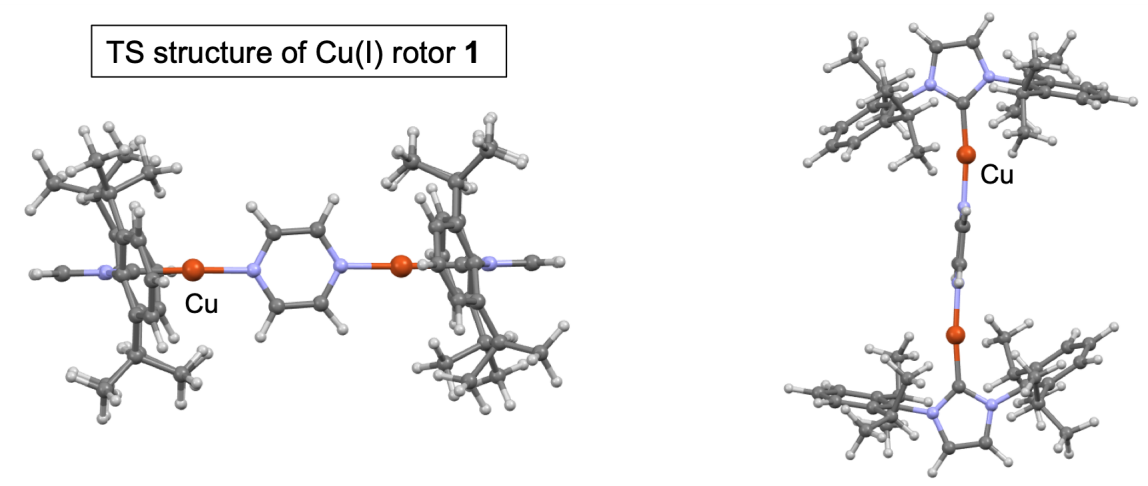

b)

TS structure of $A u(I)$ rotor 2
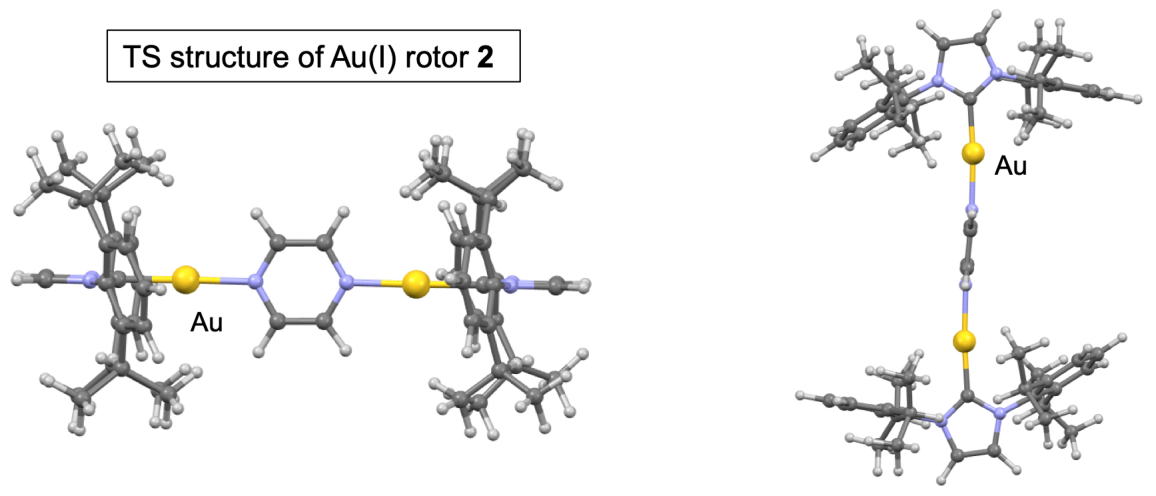

Figure S10. Geometries of the transition state (TS) of a) 1 and b) $\mathbf{2}$ obtained from the calculations.

a)

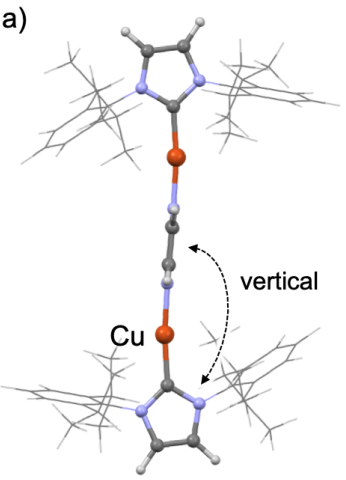

stabilization energy via

$\pi$-backdonation : $\mathrm{Cu}\left(d_{\pi}\right) \rightarrow N-C\left(\pi^{*}\right)$

$-5.2 \mathrm{kcal} / \mathrm{mol}$

(NBO analysis) b)
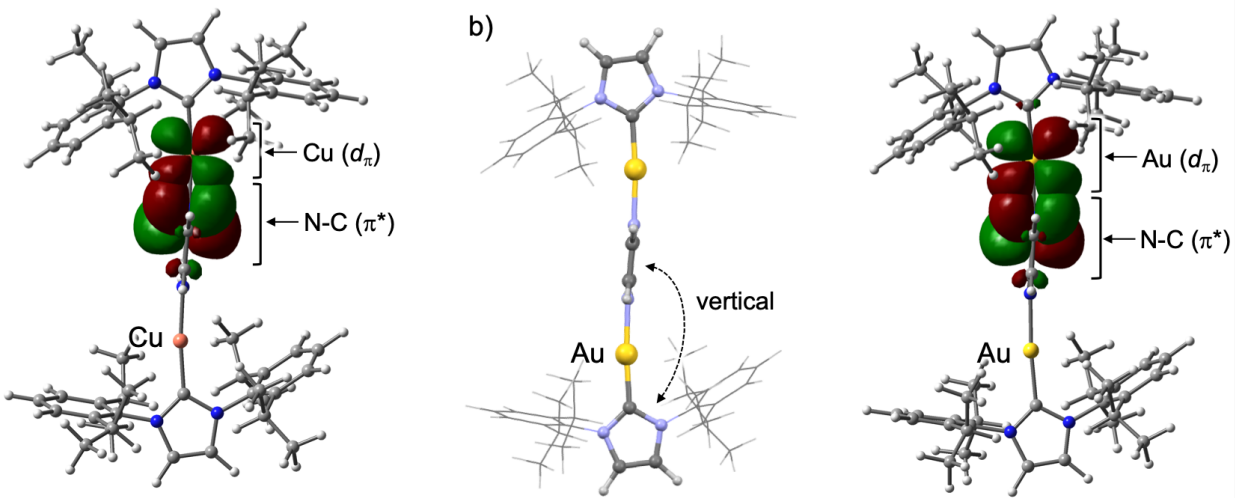

stabilization energy via

$\pi$-backdonation : $A u\left(d_{\pi}\right) \rightarrow N-C\left(\pi^{*}\right)$

$-7.2 \mathrm{kcal} / \mathrm{mol}$ (NBO analysis)

Figure S11. TS structures of the a) $\mathrm{Cu}(\mathrm{I})$ rotor 1 and b) $\mathrm{Au}(\mathrm{I})$ rotor $\mathbf{2}$ having vertical geometries between pyrazine and NHC plane (left), and the estimated $\pi$-back donation by NBO analysis (right). 

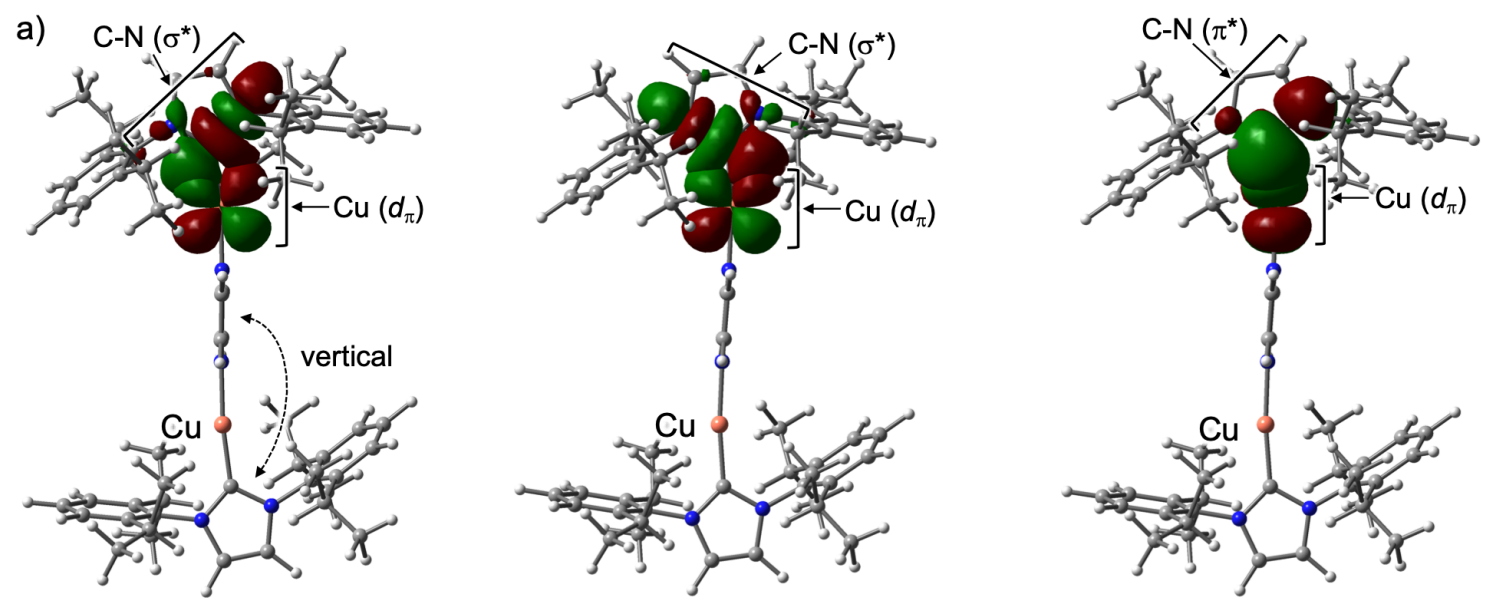

stabilization energy via

$\mathrm{Cu}\left(d_{\pi}\right) \rightarrow C-N\left(\sigma^{*}\right)$ on $N H C$

\section{$-3.8 \mathrm{kcal} / \mathrm{mol}$ \\ (NBO analysis)}

b)
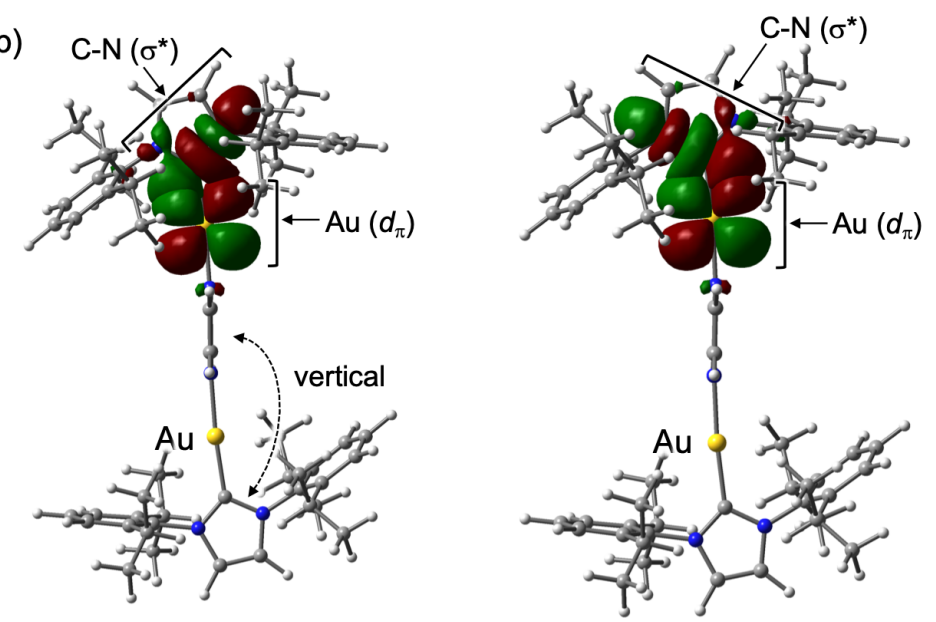

stabilization energy via

$A u\left(d_{\pi}\right) \rightarrow C-N\left(\sigma^{*}\right)$ on $N H C$

\section{$-7.8 \mathrm{kcal} / \mathrm{mol}$ \\ (NBO analysis)}

\section{stabilization energy via $\mathrm{Cu}\left(d_{\pi}\right) \rightarrow C-N\left(\pi^{*}\right)$ on $\mathrm{NHC}$ \\ $-8.3 \mathrm{kcal} / \mathrm{mol}$ \\ (NBO analysis)}

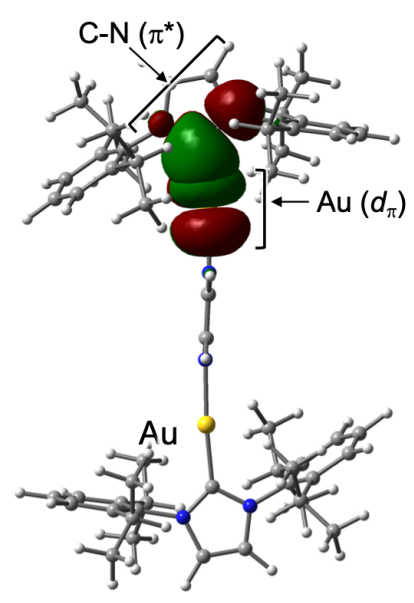

stabilization energy via $A u\left(d_{\pi}\right) \rightarrow C-N\left(\pi^{*}\right)$ on $N H C$

\section{$-15.7 \mathrm{kcal} / \mathrm{mol}$ \\ (NBO analysis)}

Figure S12. Estimated electronic interactions donating from a) $\mathrm{Cu}\left(d_{\pi}\right)$ or b) $\mathrm{Au}\left(d_{\pi}\right)$ to the $\mathrm{NHC}$ ligand by NBO analysis using the TS structures having vertical geometry between pyrazine and NHC plane. 


\subsection{Quantitative interaction analysis using I-SAPT}

To estimate the steric interactions between the IPr-NHC ligand and the pyrazine rotator, we employed the energy decomposition analysis between the diisopropylphenyl groups on the NHC ligand and the pyrazine rotator of four geometries from the ground and transition state of $\mathbf{1}$ and $\mathbf{2}$ by using intramolecular symmetry-adapted perturbation theory (I-SAPT) implemented in the PSI4 1.3 program package. ${ }^{9,10}$ This I-SAPT calculation can decompose the interaction energy between the two functional groups to physically meaningful components, including electrostatic interaction (Elst), exchange repulsion (Exch), induction effect (Ind), and dispersion interaction (Disp) terms. The reference wave function was re-calculated at SAPT0 level of theory with Sapporo-DKH3-DZP-2012 basis set for Au and Def2-SVP basis set for the other atoms, and a series of default auxiliary basis sets; Def2-SVP-JKFIT, Def2-SVP-RI, and WTBS for Au and cc-pVTZ-MINAO for the other atoms. The multiplicities of the two functional groups were set to doublet, that of the other link structure was set to singlet, and that of the overall molecule was set to singlet. Finally, it was confirmed that two link bonds were assigned into the link structure as a result of automatic IBO localization and link bond selection in the I-SAPT calculations.

Two structural combinations (I and II) between the left or right site of IPr-NHC ligand (diisopropylphenyl moiety) and pyrazine were set for the energy decomposition analysis using I-SAPT (Figure S13). The results were summarized in Table S2. It should be noted that the exchange interactions, namely steric repulsion, in the TS-1 shows ca. $1.6 \mathrm{kcal} / \mathrm{mol}$ of higher energy value than those of the TS-2. Furthermore, the gap of total SAPT energy value between the TS and ground state of $\mathrm{Cu}(\mathrm{I})$ rotor 1 also shows ca. $1.7 \mathrm{kcal} / \mathrm{mol}$ higher than those of $\mathrm{Au}(\mathrm{I})$ rotor 2 (Table $\mathrm{S} 2$ ). These results indicate that the difference in steric repulsion between TS-1 and TS-2 worked for a crucial factor in the different activation energy barrier for the two-fold pyrazine rotations between the $\mathrm{Cu}$ and $\mathrm{Au}$ rotors.

a)

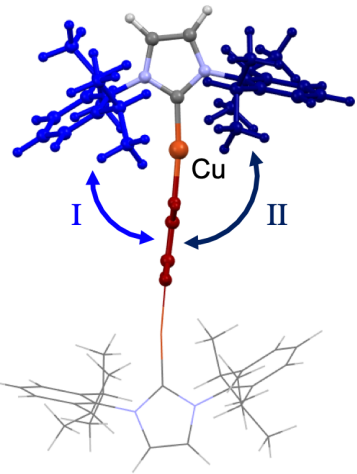

TS-1

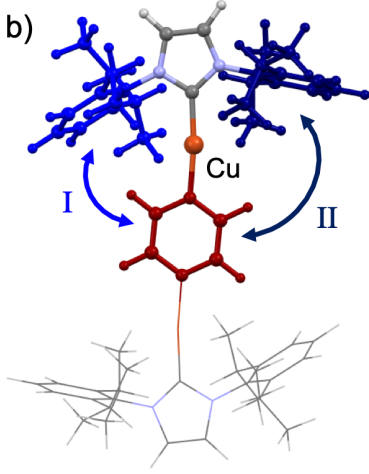

ground-1

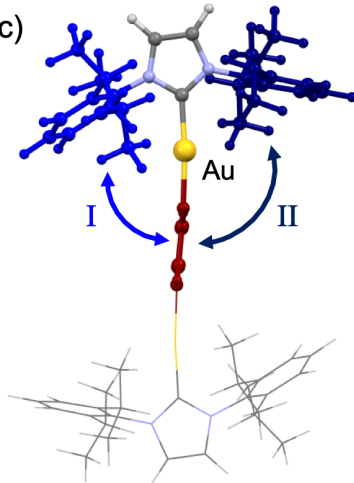

TS-2

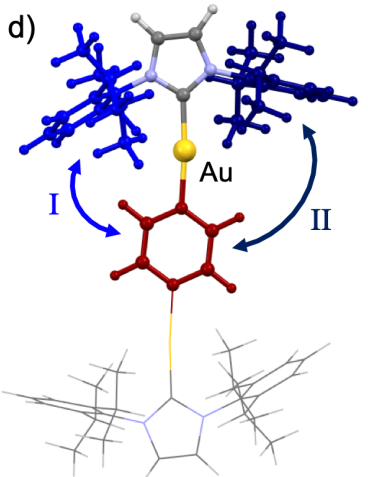

ground-2

Figure S13. The calculated structures of a) TS-1, b) ground-1, c) TS-2, and d) ground-2 with the defined structural combinations (I and II) between the diisopropylphenyl groups and pyrazine (left and right sites are illustrated in blue and dark blue, respectively). 
Table S2. Results of energy decomposition analysis using I-SAPT.

\begin{tabular}{|c|c|c|c|c|c|c|}
\hline structure & domain & $\begin{array}{c}\text { Electrostatic } \\
{[\mathrm{kcal} / \mathrm{mol}]}\end{array}$ & $\begin{array}{l}\text { Exchange } \\
{[\mathrm{kcal} / \mathrm{mol}]}\end{array}$ & $\begin{array}{l}\text { Induction } \\
{[\mathrm{kcal} / \mathrm{mol}]}\end{array}$ & $\begin{array}{l}\text { Dispersion } \\
{[\mathrm{kcal} / \mathrm{mol}]}\end{array}$ & $\begin{array}{c}\text { Total } \\
{[\mathrm{kcal} / \mathrm{mol}]}\end{array}$ \\
\hline \multirow{3}{*}{ TS-1 } & I & 0.72 & 3.80 & -0.77 & -2.52 & \\
\hline & II & 0.71 & 0.41 & -0.19 & -1.12 & \\
\hline & $\mathrm{I}+\mathrm{II}$ & 1.43 & 4.21 & -0.96 & -3.64 & 1.03 \\
\hline \multirow{4}{*}{ ground-1 } & I & -0.94 & 1.86 & -0.78 & -2.49 & \\
\hline & II & 0.30 & 0.26 & -0.22 & -0.99 & \\
\hline & $\mathrm{I}+\mathrm{II}$ & -0.64 & 2.12 & -1.00 & -3.48 & -3.01 \\
\hline & & & & \multicolumn{2}{|c|}{ TS-1 (I+II) - ground-1 (I+II) } & 4.04 \\
\hline \multirow{3}{*}{ TS -2 } & I & 0.39 & 2.01 & -0.34 & -1.77 & \\
\hline & II & 0.32 & 0.58 & -0.12 & -0.80 & \\
\hline & $\mathrm{I}+\mathrm{II}$ & 0.71 & 2.59 & -0.46 & -2.57 & 0.28 \\
\hline \multirow{4}{*}{ ground-2 } & I & -0.62 & 1.23 & -0.41 & -1.83 & \\
\hline & II & 0.00 & 0.49 & -0.14 & -0.72 & \\
\hline & $\mathrm{I}+\mathrm{II}$ & -0.62 & 1.72 & -0.55 & -2.55 & -1.99 \\
\hline & & & & \multicolumn{2}{|c|}{ TS-2 (I+II) - ground-2 (I+II) } & 2.27 \\
\hline
\end{tabular}

\subsection{Details of calculation study using the modeled rotors}

To confirm the contribution of $\pi$-back donation on the molecular rotation, we performed the DFT calculation using the modeled rotors possessing non-bulky NHC ligand. The initial geometries of the modeled rotors were built from the ground state structures of $\mathrm{Cu}(\mathrm{I})$ rotor $\mathbf{1}$ and $\mathrm{Au}(\mathrm{I})$ rotor 2 with substituting diisopropylphenyl group to methyl group on the NHC ligand. It is followed by optimizing the positions of $\mathrm{H}$ atoms by fixing the geometries of heavy atoms using DFT calculation with B3LYP/6-31G level. The ground state and TS structures for the molecular rotations were obtained by the Locally Updated Planes (LUP) method using the GRRM17 program ${ }^{4-6}$. The geometry optimizations were performed under $\omega \mathrm{B} 97 \mathrm{XD} / 6-31 \mathrm{G}(\mathrm{d})$ for organic atoms and LanL2DZ for metals with fixing whole atoms without pyrazine rotator. Interestingly, the structure having vertical geometry between pyrazine and NHC plane was assigned as a ground state in both rotors, which is opposite from the cases of rotor 1 and $\mathbf{2}$ (Figure S14a and b). NBO analysis using the ground state geometries of the modeled rotors revealed that the Au rotor shows ca. $1.5 \mathrm{kcal} / \mathrm{mol}$ of stronger $\pi$-back donation energy than those of the Cu rotor, as shown in Figure S15c and d, which is almost the same as the cases using the TS structures of rotor $\mathbf{1}$ and $\mathbf{2}$. These results indicated that the vertical geometry between pyrazine and NHC plane conduct stabilizing effect via $\pi$-back donation from $d_{\pi}$ of metals to $\pi^{*}$ of pyrazine, and the magnitude of the stabilized energy could be modulated by altering metal species which have different size of $d_{\pi}$ orbitals. 

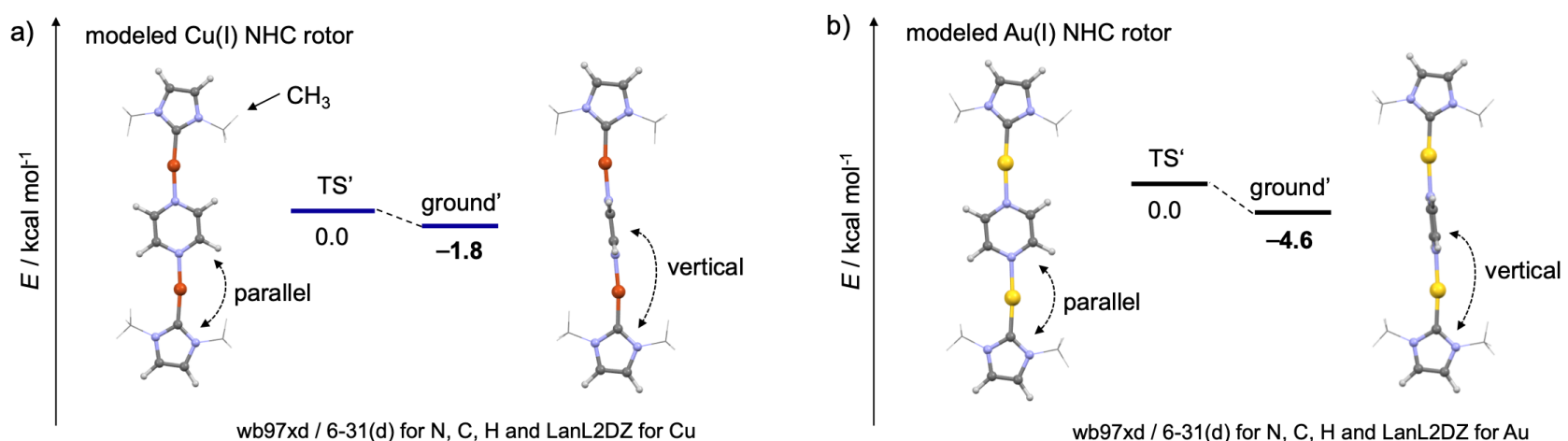

Figure S14. Energy diagrams and the obtained geometries of the ground state and TS for molecular rotation in the modeled a) $\mathrm{Cu}(\mathrm{I})$ rotor and $\mathrm{b}) \mathrm{Au}(\mathrm{I})$ rotor.

a)

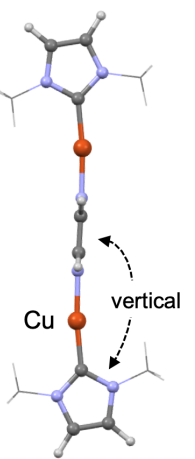

stabilization energy via

$\pi$-backdonation : $\mathrm{Cu}\left(d_{\pi}\right) \rightarrow N-C\left(\pi^{*}\right)$

$-5.4 \mathrm{kcal} / \mathrm{mol}$ (NBO analysis)

c)

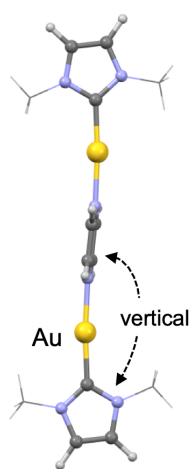

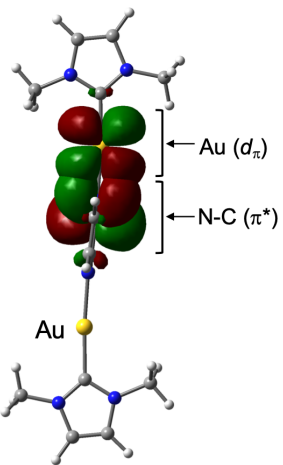

stabilization energy via $\pi$-backdonation : $A u\left(d_{\pi}\right) \rightarrow N-C\left(\pi^{*}\right)$

$-6.9 \mathrm{kcal} / \mathrm{mol}$ (NBO analysis) b)
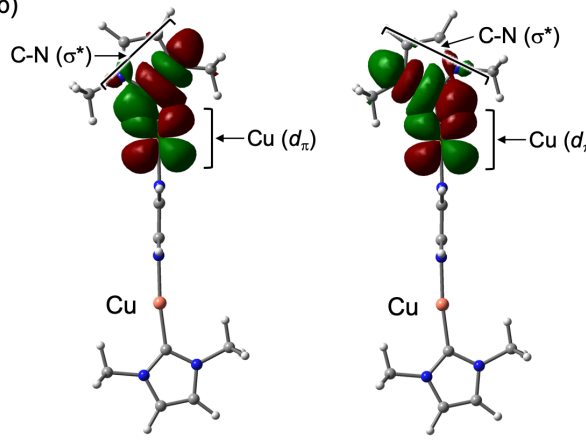

stabilization energy via $\mathrm{Cu}\left(d_{\pi}\right) \rightarrow \mathrm{C}-\mathrm{N}\left(\sigma^{*}\right)$ on $\mathrm{NHC}$

-3.7 kcal / mol (NBO analysis)

d)
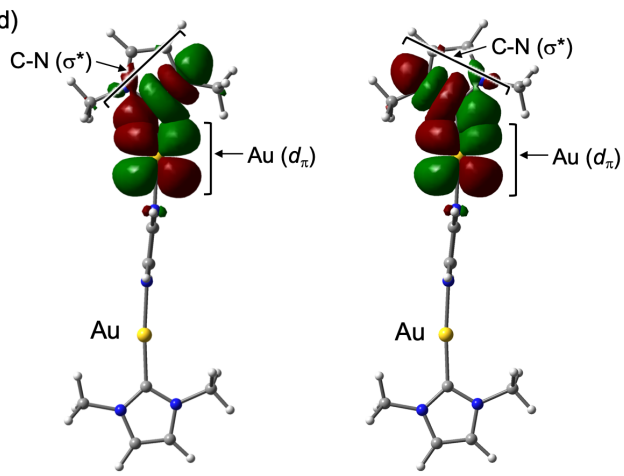

stabilization energy via $A u\left(d_{\pi}\right) \rightarrow C-N\left(\sigma^{*}\right)$ on $N H C$

$-7.5 \mathrm{kcal} / \mathrm{mol}$ (NBO analysis)

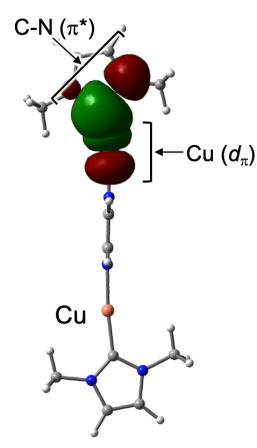

stabilization energy via $\mathrm{Cu}\left(d_{\pi}\right) \rightarrow C-N\left(\pi^{*}\right)$ on $N H C$

$-7.9 \mathrm{kcal} / \mathrm{mol}$ (NBO analysis)
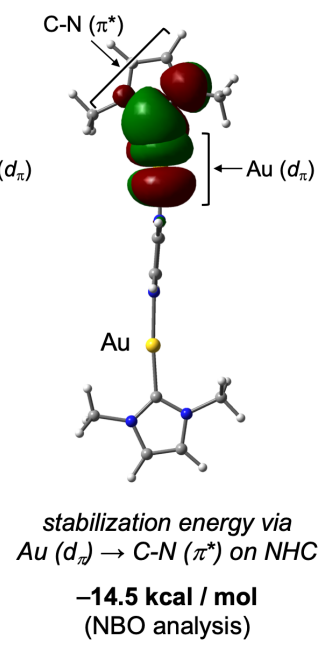

Figure S15. Estimated $\pi$-back donation energy of the a) $\mathrm{Cu}(\mathrm{I})$ rotor and c) $\mathrm{Au}(\mathrm{I})$ rotor, and other electronic interactions donating from b) $\mathrm{Cu}\left(d_{\pi}\right)$ or d) $\mathrm{Au}\left(d_{\pi}\right)$ to the NHC ligand by NBO analysis using the vertical geometry between pyrazine and NHC plane. 


\subsection{Analysis of the obtained energy diagrams}

We used different analysis methods for evaluation of the steric repulsions and $\pi$-back donation energies between the $\mathrm{Cu}$ and $\mathrm{Au}$ rotors by using I-SAPT and NBO analysis, respectively. This analysis reveals the energy trends between $\mathrm{Cu}$ and $\mathrm{Au}$ rotors $(\mathrm{Cu}>\mathrm{Au}$ for steric repulsion and $\mathrm{Cu}<\mathrm{Au}$ for stabilization via $\pi$-back donation) in their transition states. Because of the difference in the calculation methods and the unevaluated energies originated by the crystal lattice, the simple sums of the energies of steric repulsion (I-SAPT) and p-back donation (NBO) are not consistent with the activation energies obtained by experiments and calculations.

In order to understand how the energy barriers for the rotations are composed, we suppose a hypothetical model of the energy diagram, as shown Figure S16. Simple summing the steric repulsion energy (red arrow) and the stabilization energy via p-back donation (blue arrow) were not match with the calculated energy barriers for the rotation in both the $\mathrm{Cu}$ and Au rotors. The energy gaps caused by some destabilized lattice energies and systematic errors caused by the use of the different calculation methods were illustrated in a gray bar $(\approx 10 \mathrm{kcal} / \mathrm{mol}$ for each $)$. We expected that the destabilization lattice energies may contain some destabilized strains or bonds of the NHC metal complexes at the TS, which can be caused by the frozen operations of stators and axis during the calculations to approximate the environment of the crystal structures.

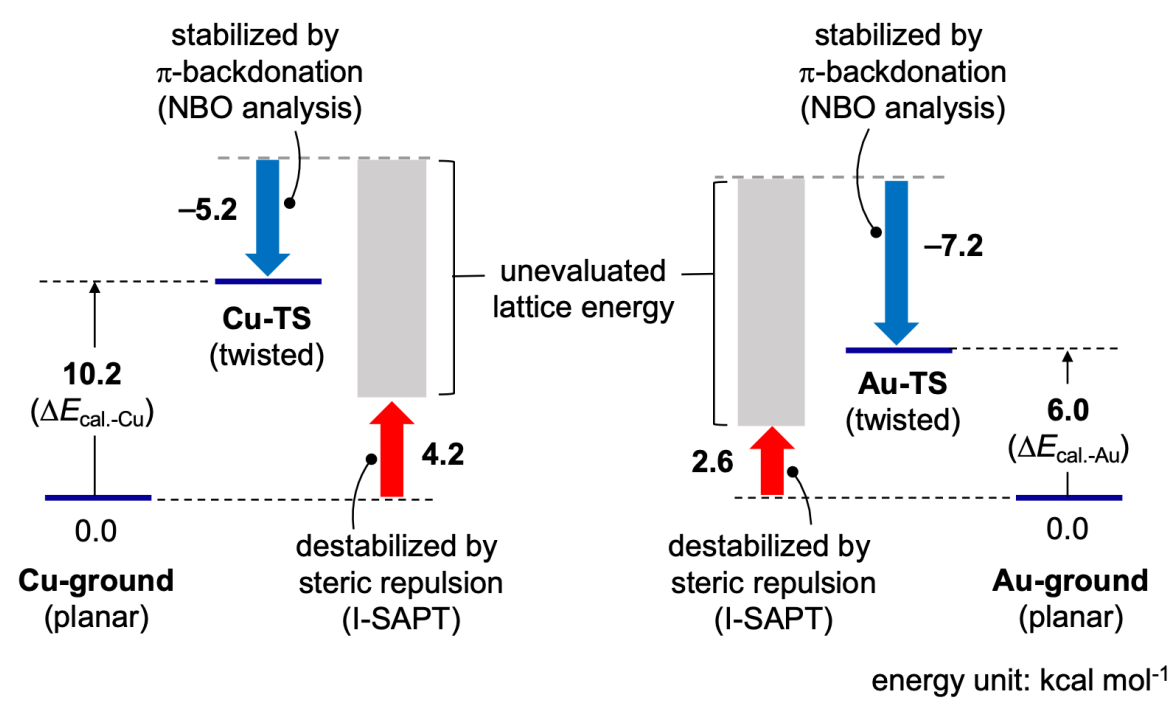

Figure S16. Representation of hypothesis for analyzing the energy diagram. 


\section{Optical Properties of Solution Phase of 1 and 2}

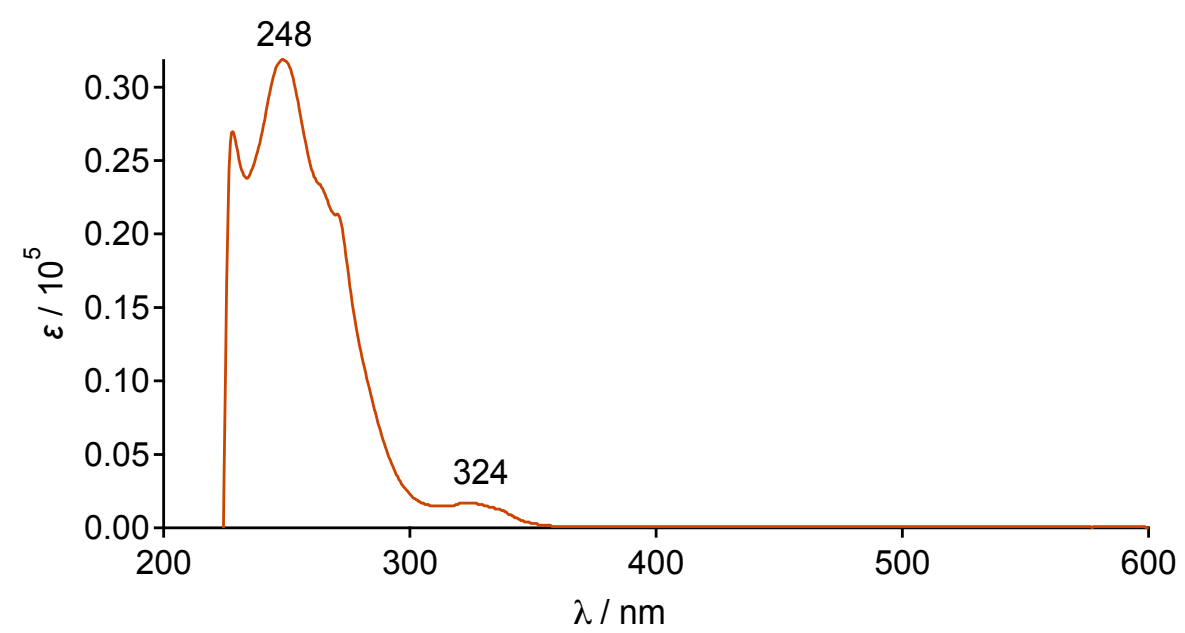

Figure S17. UV/vis of $\mathrm{Cu}(\mathrm{I})$ rotor 1 in $\mathrm{CH}_{2} \mathrm{Cl}_{2}\left(c=6.2 \times 10^{-6} \mathrm{M}\right)$ at room temperature. The solution of 1 in $\mathrm{CH}_{2} \mathrm{Cl}_{2}$ exhibited no emission under UV light.

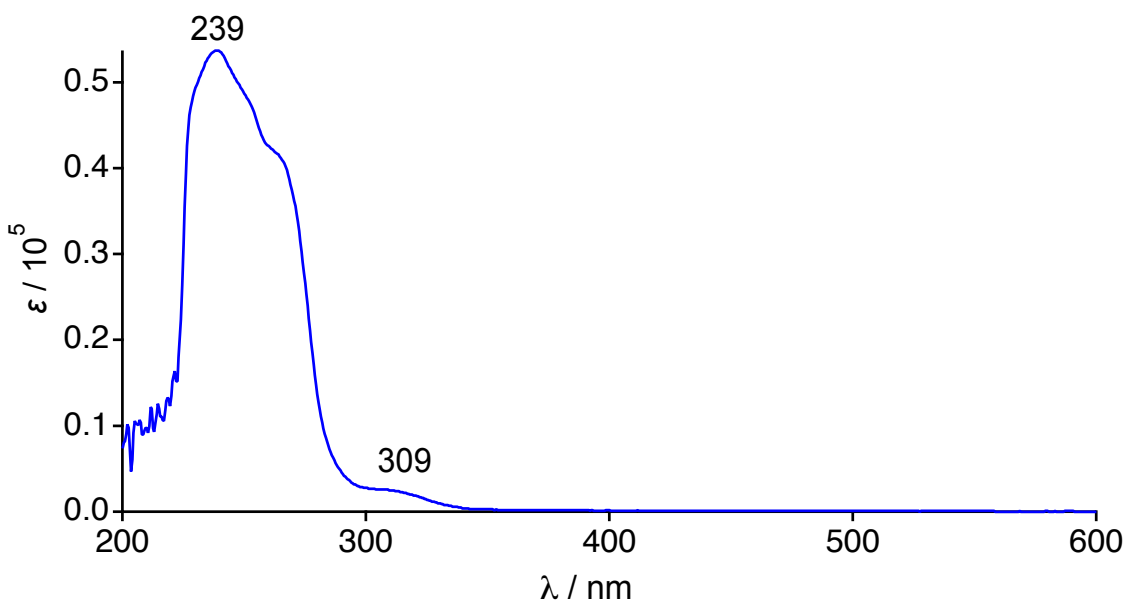

Figure S18. UV/vis of $\mathrm{Au}(\mathrm{I})$ rotor 2 in $\mathrm{CH}_{2} \mathrm{Cl}_{2}\left(c=3.6 \times 10^{-5} \mathrm{M}\right)$ at room temperature. The solution of 2 in $\mathrm{CH}_{2} \mathrm{Cl}_{2}$ exhibited no emission under UV light. 


\section{Photophysical Properties}

For emission decay traces of crystal 1, we used $370 \mathrm{~nm}$ as the excitation wavelength and detected kinetic traces at $600 \mathrm{~nm}$. Emission decays of crystal 2 were detected at $420 \mathrm{~nm}$ under $370 \mathrm{~nm}$ excitation. The emission decays were measured under $10^{4}$ counts. The obtained emission decays were fitted by using second-order exponential decay function. The absolute emission quantum yield $\Phi$ of both crystalline rotors were measured by setting ca. $10 \mathrm{mg}$ of the crystalline samples into a Hamamatsu Quantaurus-QY spectrometer with an integrating sphere.
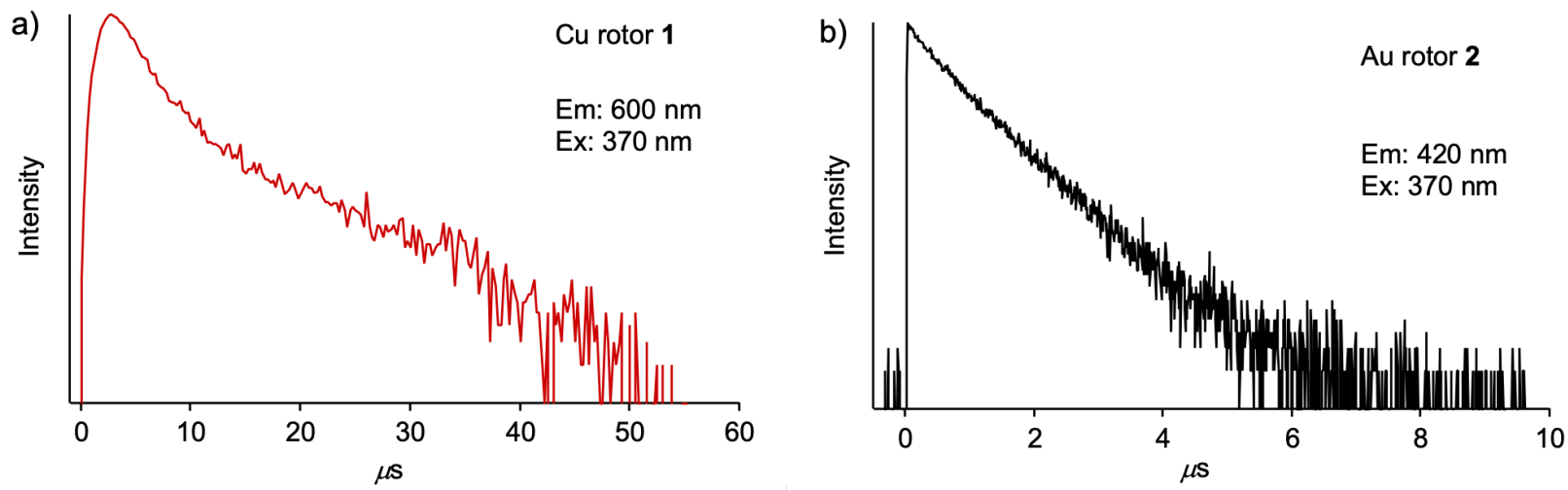

Figure S19. Emission decay profiles of the crystal a) 1 and b) 2 measured at room temperatures. The emission decays were monitored at a) $600 \mathrm{~nm}$ and b) $420 \mathrm{~nm}$ under $370 \mathrm{~nm}$ of excitation.

Table S3. Emission lifetimes fitted from the emission decays and quantum yield of crystal $\mathbf{1}$ and $\mathbf{2}$

\begin{tabular}{cccccc}
\hline Sample & $\tau_{a v} / \mu \mathrm{s}^{\mathrm{a}, \mathrm{b}}$ & $\begin{array}{c}\tau_{1} / \mu \mathrm{s}^{\mathrm{a}} \\
(A /-)\end{array}$ & $\begin{array}{c}\tau_{2} / \mu \mathrm{s}^{\mathrm{a}} \\
(A /-)\end{array}$ & CHI & $\Phi^{\mathrm{c}}$ \\
\hline crystal 1 & 3.06 & 1.69 & 18.9 & 1.19 & 0.14 \\
& & $(0.92)$ & $(0.08)$ & & \\
crystal 2 & 0.87 & 0.38 & 0.95 & 1.03 & 0.12 \\
& & $(0.13)$ & $(0.87)$ & & \\
\hline
\end{tabular}

a: $\lambda_{e x}=370 \mathrm{~nm}, \lambda_{e m}=600 \mathrm{~nm}$ for crystal 1 and $\lambda_{e m}=420 \mathrm{~nm}$ for crystal $2 .{ }^{\mathrm{b}}: \tau_{a v}=\Sigma \tau_{\mathrm{n}} A_{\mathrm{n}}{ }{ }^{\mathrm{c}}: \lambda_{e x}=380 \mathrm{~nm}$ for crystal 1 and $\lambda_{e x}=345 \mathrm{~nm}$ for crystal 2. 


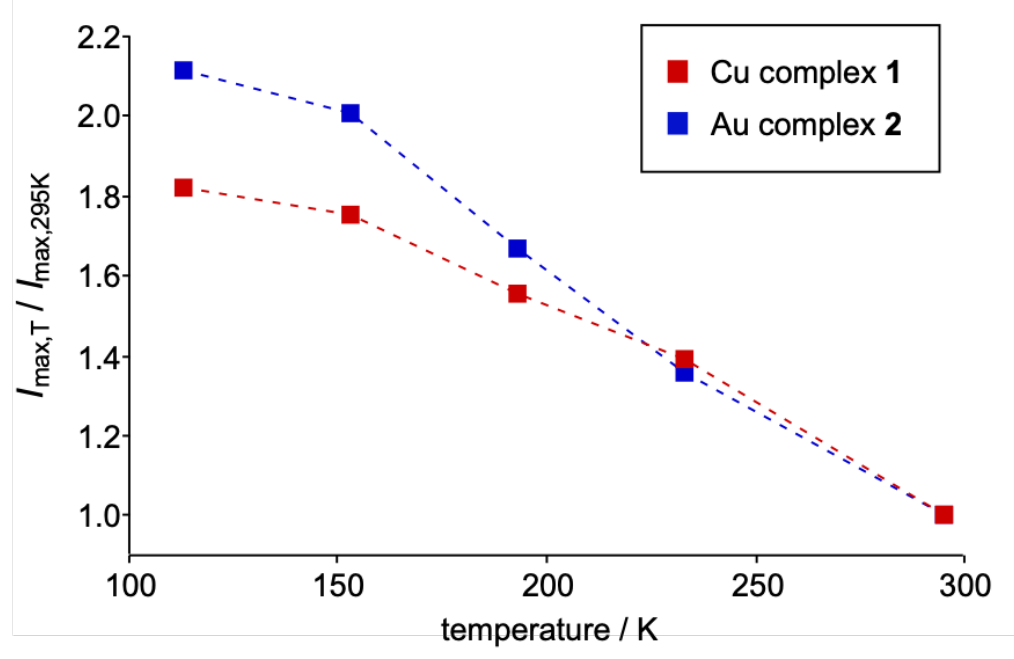

Figure S20. Plot of changes in the ratio of maximum emission intensity between the intensity at measured temperature $\left(I_{\max , \mathrm{T}}\right)$ and at $295 \mathrm{~K}\left(I_{\max , 295 \mathrm{~K}}\right)$ as a function of temperature. The plots for $\mathrm{Cu}$ complex $\mathbf{1}$ and Au complex $\mathbf{2}$ were described in red and blue square, respectively. 


\section{TD-DFT Calculations}

All calculations were performed using the Gaussian 16 (revision C.01 and E.01) program package ${ }^{3}$. The singlet state TD-DFT calculations of the $\mathrm{Cu}$ and $\mathrm{Au}$ rotors in the crystal $\mathbf{1}$ and $\mathbf{2}$ were performed with the goal of understanding the origin of their emission properties. In the calculations, the B3LYP functional and the SDD basis set with an effective core potential for metals and the 6-31G* for the other atoms were used. The geometries of the rotor 1 and 2 with $\mathrm{SbF}_{6}{ }^{-1}$ anion were taken from the single-crystal structure of $\mathbf{1}$ and $\mathbf{2}$ at $195 \mathrm{~K}$. The positions of the heavy atoms were fixed and only the positions of $\mathrm{H}$ atoms were optimized using the DFT calculations under B3LYP/6-31G* before TDDFT calculations ${ }^{3}$. The simulated UV/vis absorption spectra and the excitation spectra from the experiments exhibited a similar tendency on the traces (Figure S18).
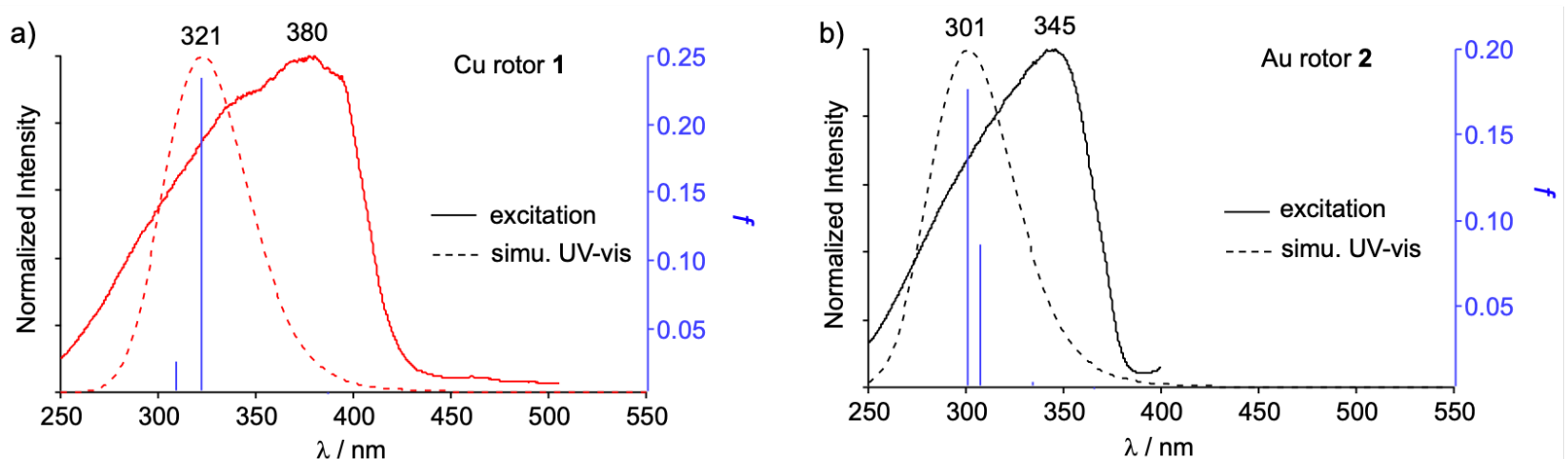

Figure S21. Comparison of experimental and theoretical studies on emission properties of the crystal a) 1 and b) 2. Excitation spectra of the crystal 1 and $\mathbf{2}$ (red and black solid line, respectively) obtained at room temperature. Simulated UV/vis absorption spectra of the rotor $\mathbf{1}$ and $\mathbf{2}$ in the crystals (red and black dashed line, respectively) and oscillator strengths (blue sticks) based on the singlet state TDDFT calculations of the geometries derived from the single crystalline structures of $\mathbf{1}$ and $\mathbf{2}$ measured at room temperature (B3LYP/6-31G* for $\mathrm{C}, \mathrm{H}, \mathrm{N}, \mathrm{F}$ and $\mathrm{SDD}$ for $\mathrm{Cu}$ or $\mathrm{Au}$ ). 
Table S4. Selected singlet to singlet transitions of the $\mathrm{Cu}(\mathrm{I})$ rotor 1

\begin{tabular}{cccccc}
\hline states & energy / eV & $\lambda / \mathrm{nm}$ & $f /-$ & orbital transition & Cl coefficients \\
\hline S0 to S1 & 3.3025 & 387 & 0.0033 & $\begin{array}{c}\text { HOMO-10 } \rightarrow \text { LUMO } \\
\text { HOMO-4 } \rightarrow \text { LUMO }\end{array}$ & 0.11259 \\
& & & & HOMO $\rightarrow$ LUMO & 0.41064 \\
& & & & & 0.55397 \\
S0 to S7 & 3.8525 & \multirow{2}{*}{321} & \multirow{2}{*}{0.2343} & HOMO-8 $\rightarrow$ LUMO & 0.38207 \\
& & & & HOMO-6 $\rightarrow$ LUMO & 0.57334 \\
S0 to S9 & 4.0075 & \multirow{2}{*}{309} & \multirow{2}{*}{0.0265} & HOMO-10 $\rightarrow$ LUMO & -0.21415 \\
& & & & HOMO-8 $\rightarrow$ LUMO & 0.55104 \\
& & & & HOMO-6 $\rightarrow$ LUMO & -0.37157 \\
\hline
\end{tabular}

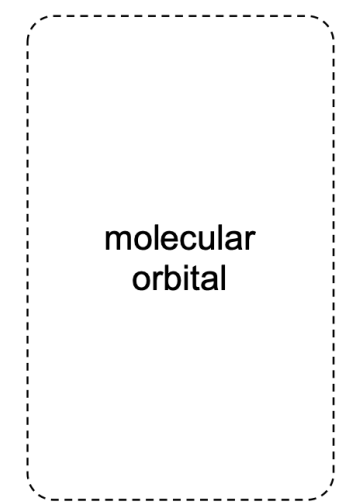

state

(hartree)

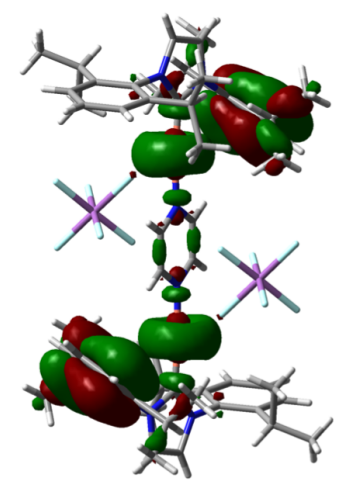

HOMO

$(-0.24692)$

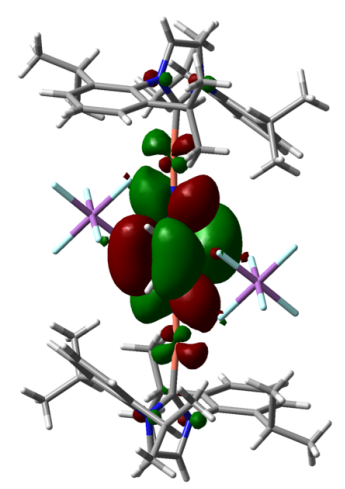

LUMO

$(-0.09810)$

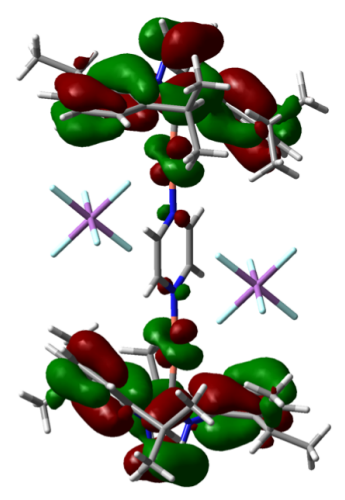

HOMO-6

$(-0.26157)$

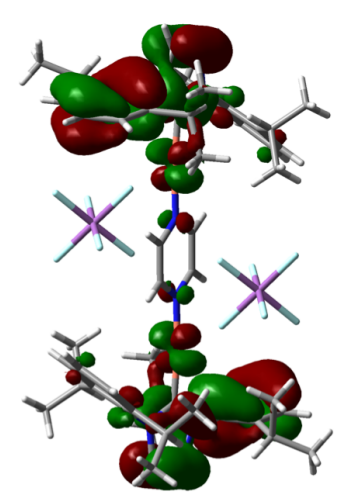

HOMO-8

$(-0.26418)$ 
Table S5. Selected singlet to singlet transitions of the $\mathrm{Au}(\mathrm{I})$ rotor 2

\begin{tabular}{|c|c|c|c|c|c|}
\hline states & energy /eV & $\lambda / \mathrm{nm}$ & $f /-$ & orbital transition & $\mathrm{Cl}$ coefficients \\
\hline \multirow[t]{2}{*}{ S0 to S1 } & 3.388 & 366 & 0.0027 & HOMO-4 $\rightarrow$ LUMO & -0.10590 \\
\hline & & & & HOMO $\rightarrow$ LUMO & 0.69434 \\
\hline \multirow[t]{4}{*}{ S0 to S7 } & 4.0281 & 308 & 0.0858 & HOMO-12 $\rightarrow$ LUMO & -0.17437 \\
\hline & & & & HOMO-8 $\rightarrow$ LUMO & 0.22488 \\
\hline & & & & HOMO-6 $\rightarrow$ LUMO & 0.60482 \\
\hline & & & & HOMO-4 $\rightarrow$ LUMO & -0.21970 \\
\hline \multirow[t]{2}{*}{ So to S9 } & 4.1234 & 301 & 0.1763 & HOMO-6 $\rightarrow$ LUMO & 0.65359 \\
\hline & & & & HOMO-4 $\rightarrow$ LUMO & -0.26012 \\
\hline
\end{tabular}

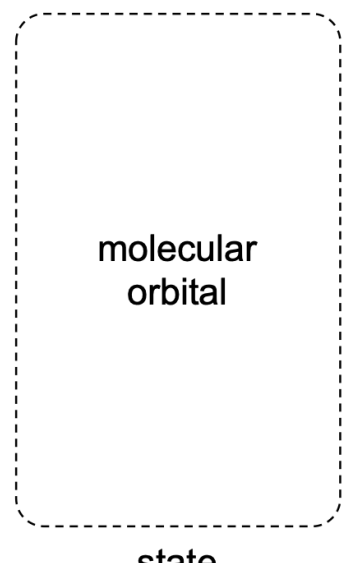

state

(hartree)

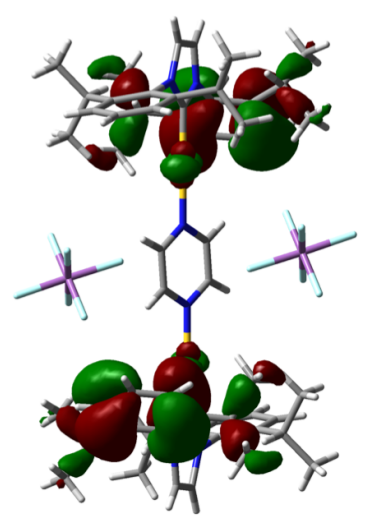

HOMO

$(-0.24967)$

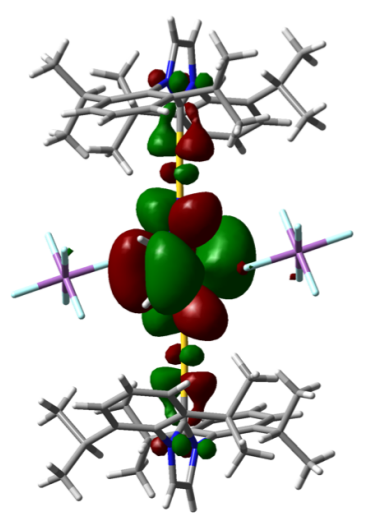

$$
\begin{gathered}
\text { LUMO } \\
(-0.10620)
\end{gathered}
$$

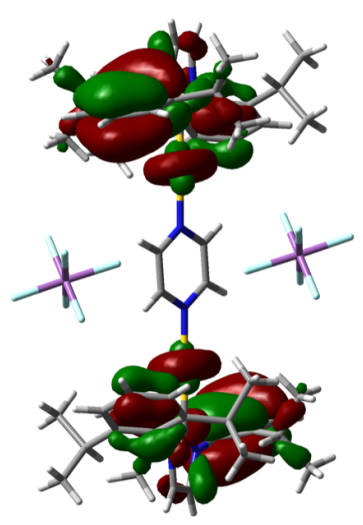

HOMO-6

$(-0.27293)$

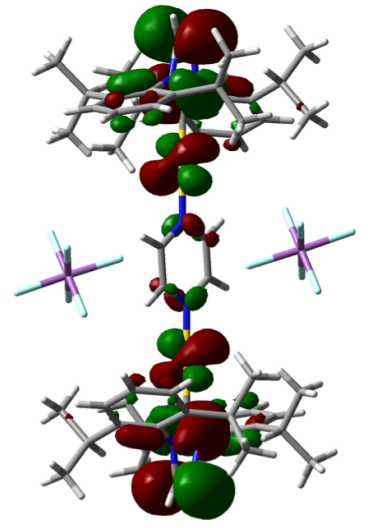

HOMO-8

$(-0.27599)$ 


\section{References}

1. Sheldrick, G. M. SHELXL-2013, Program for the Refinement of Crystal Structures; University of Göttingen, Göttingen, Germany, 2013.

2. Macho, V.; Brombacher, L.; Spiess, H. W. Appl. Magn. Reson. 2001, 20, 405. For the online program, visit: http://weblab.mpip-mainz.mpg.de/weblab/

3. Gaussian 16, Revision B.01, Frisch, M. J.; Trucks, G. W.; Schlegel, H. B.; Scuseria, G. E.; Robb, M. A.; Cheeseman, J. R.; Scalmani, G.; Barone, V.; Petersson, G. A.; Nakatsuji, H.; Li, X.; Caricato, M.; Marenich, A. V.; Bloino, J.; Janesko, B. G.; Gomperts, R.; Mennucci, B.; Hratchian, H. P.; Ortiz, J. V.; Izmaylov, A. F.; Sonnenberg, J. L.; Williams-Young, D.; Ding, F.; Lipparini, F.; Egidi, F.; Goings, J.; Peng, B.; Petrone, A.; Henderson, T.; Ranasinghe, D.; Zakrzewski, V. G.; Gao, J.; Rega, N.; Zheng, G.; Liang, W.; Hada, M.; Ehara, M.; Toyota, K.; Fukuda, R.; Hasegawa, J.; Ishida, M.; Nakajima, T.; Honda, Y.; Kitao, O.; Nakai, H.; Vreven, T.; Throssell, K.; Montgomery, Jr. J. A.; Peralta, J. E.; Ogliaro, F.; Bearpark, M. J.; Heyd, J. J.; Brothers, E. N.; Kudin, K. N.; Staroverov, V. N.; Keith, T. A.; Kobayashi, R.; Normand, J.; Raghavachari, K.; Rendell, A. P.; Burant, J. C.; Iyengar, S. S.; Tomasi, J.; Cossi, M.; Millam, J. M.; Klene, M.; Adamo, C.; Cammi, R.; Ochterski, J. W.; Martin, R. L.; Morokuma, K.; Farkas, O.; Foresman, J. B. and Fox, D. J., Gaussian, Inc., Wallingford CT, 2016.

4. GRRM17, Maeda, S., Harabuchi, Y., Sumiya, Y., Takagi, M., Suzuki, K., Hatanaka, M., Osada, Y., Taketsugu, T., Morokuma, K., Ohno, K. see http://iqce.jp/GRRM/index_e.shtml (accessed date DAY MONTH, YEAR).7.

5. Choi, C. \& Elber, R. Reaction Path Study of Helix Formation in Tetrapeptides: Effect of Side Chains, J. Chem. Phys. 94, 751-760 (1991).

6. Ayala, P. Y. \& Schlegel, H. B. A Combined Method for Determining Reaction Paths, Minima, and Transition State Geometries. J. Chem. Phys. 107, 375-384 (1997).

7. $\quad$ NBO 7.0, Glendening, E. D., Badenhoop, J, K., Reed, A. E., Carpenter, J. E., Bohmann, J. A., Morales, C. M., Karafiloglou, P., Landis, C. R. \& Weinhold, F. Theoretical Chemistry Institute, University of Wisconsin, Madison (2018).

8. Glendening, E. D., Landis, C. R. \& Weinhold, F. Natural Bond Orbital Methods. WIREs Comput. Mol. Sci. 2, 1-42 (2012).

9. Parrish, R. M., Gonthier, J. F., Corminbœuf, C. \& Sherrill, C. D. Communication: Practical Intramolecular Symmetry Adapted Perturbation Theory via Hartree-Fock embedding, J. Chem. Phys. 143, 051103 (2015).

10. Parrish, R. M., Burns, L. A., Smith, D. G. A., Simmonett, A. C., DePrince, A. E., Hohenstein, E. G., Bozkaya, U., Sokolov, A. Y., Di Remigio, R., Richard, R. M., Gonthier, J. F., James, A. M., McAlexander, H. R., Kumar, A., Saitow, M., Wang, X., Pritchard, B. P., Verma, P., \& Schaefer, H. F. et al. Psi4 1.1: An Open-source Electronic Structure Program Emphasizing Automation, Advanced Libraries, and Interoperability, J. Chem. Theory Comput. 13, 31853197 (2017). 


\section{NMR Spectra}

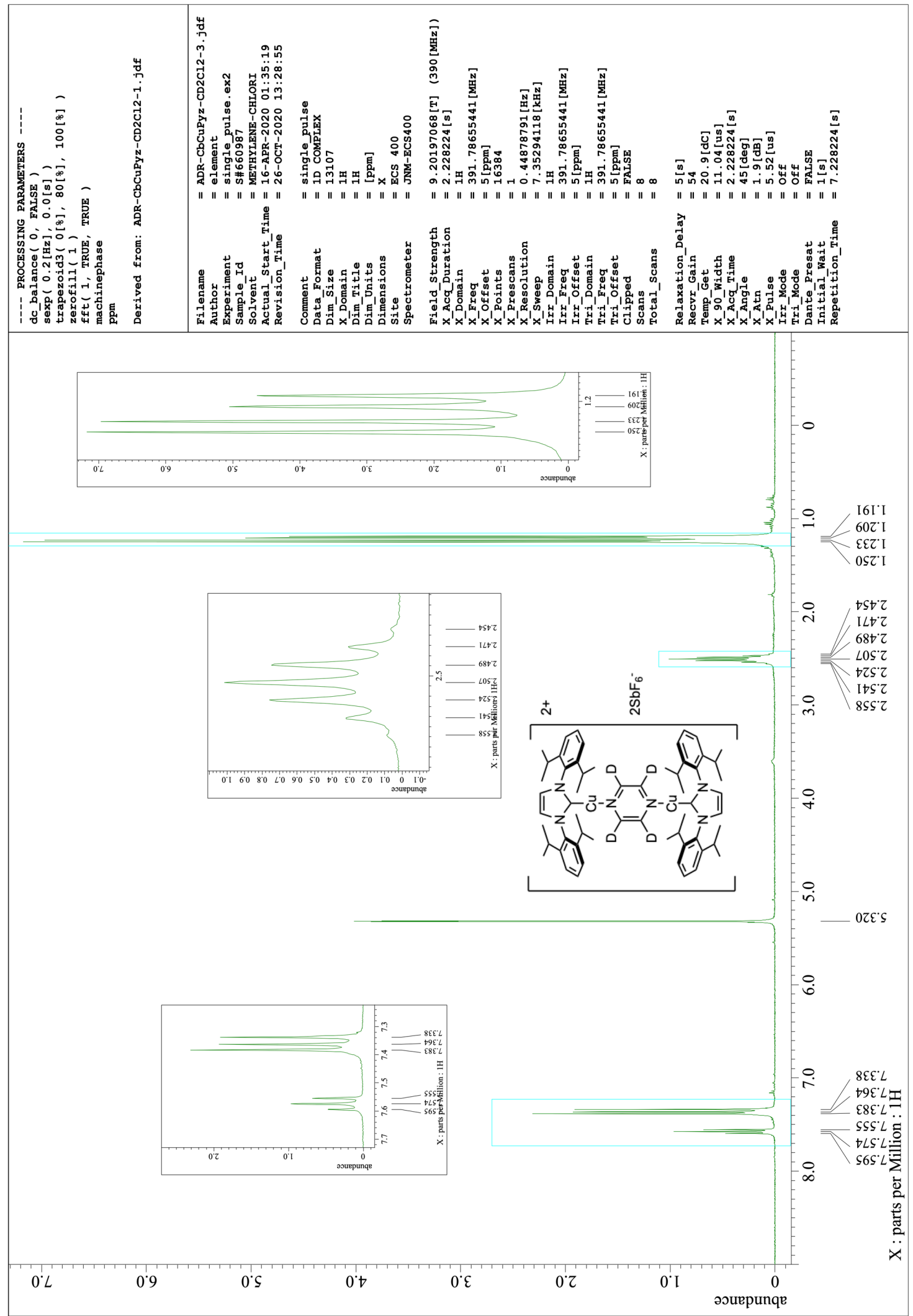




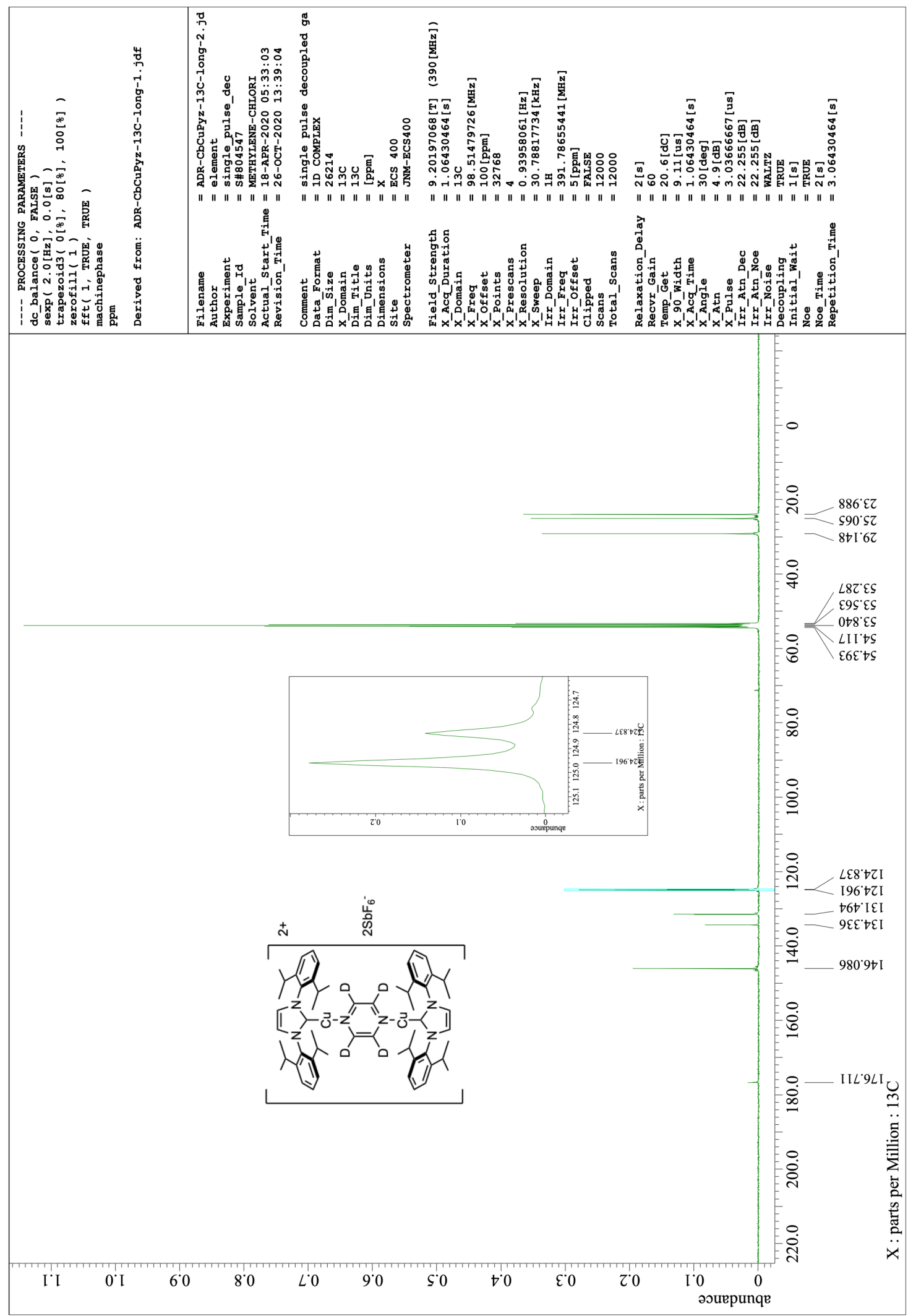




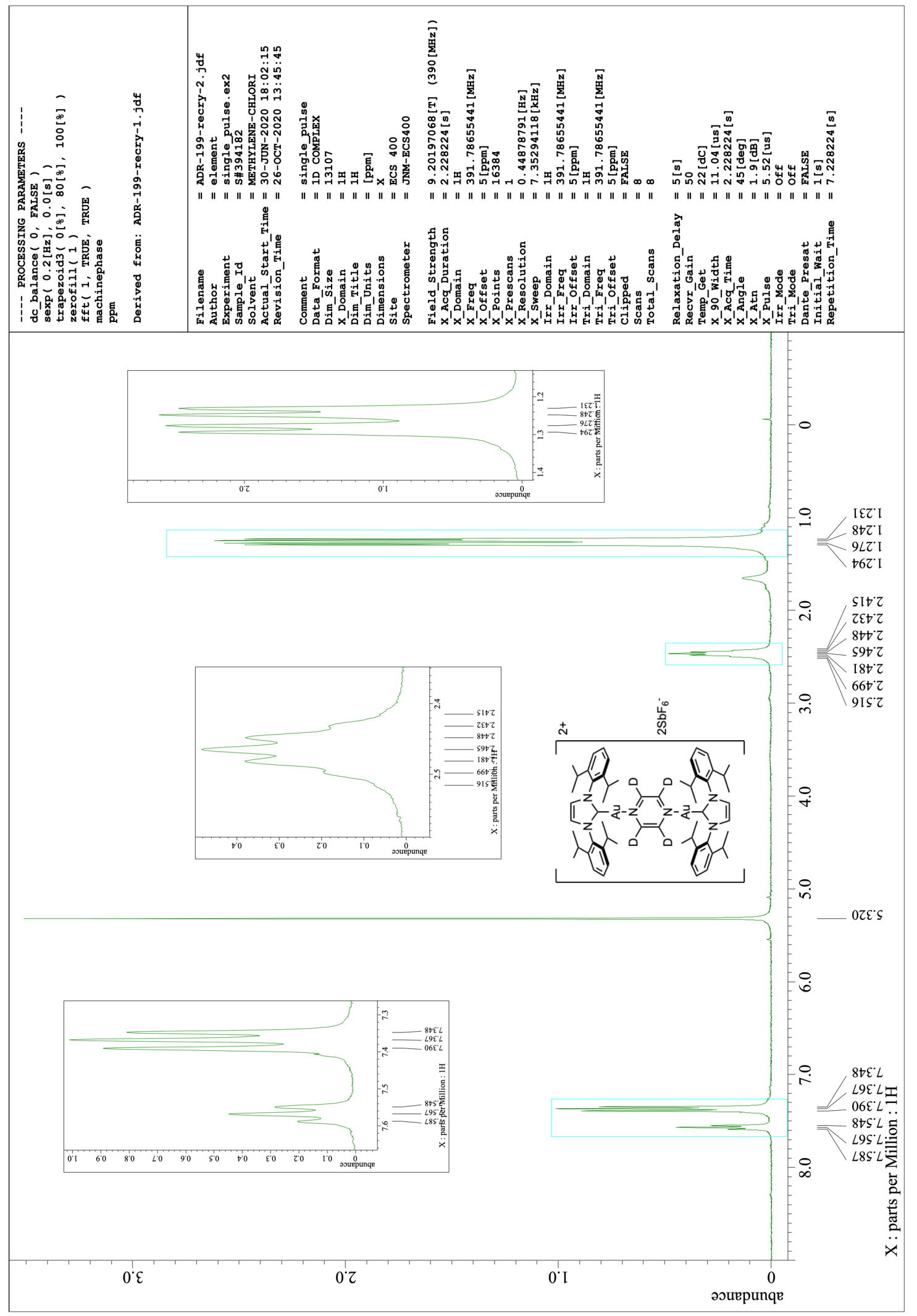




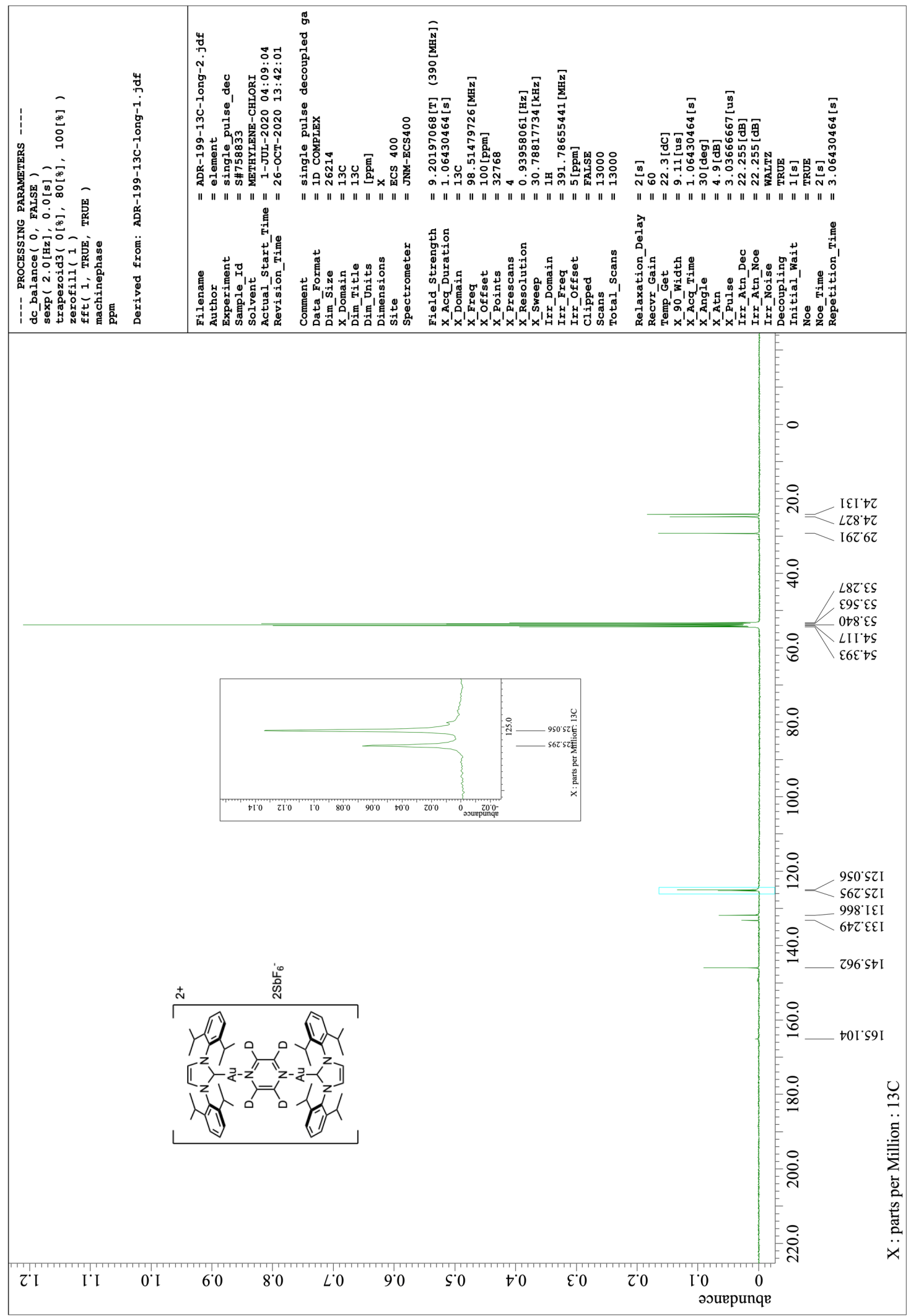

